Universidad de Lima

Escuela de Posgrado

Maestría en Derecho Empresarial

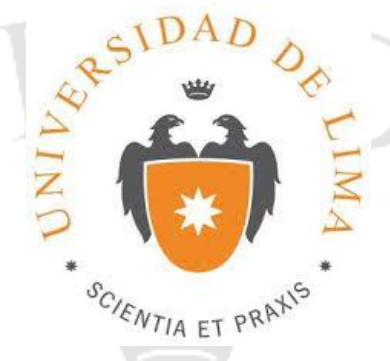

\title{
REVISIÓN DEL ARBITRAJE POTESTATIVO COMO MECANISMO DE SOLUCIÓN DE CONFLICTOS LABORALES
}

Tesis para optar por el Grado Académico de Maestro en Derecho Empresarial

Carlos Llaja Villena - Código 20011220

Johnny Fernando Pavic Espinoza - Código 20011319

Asesor: Germán Lora

Lima - Perú

Julio de 2018 


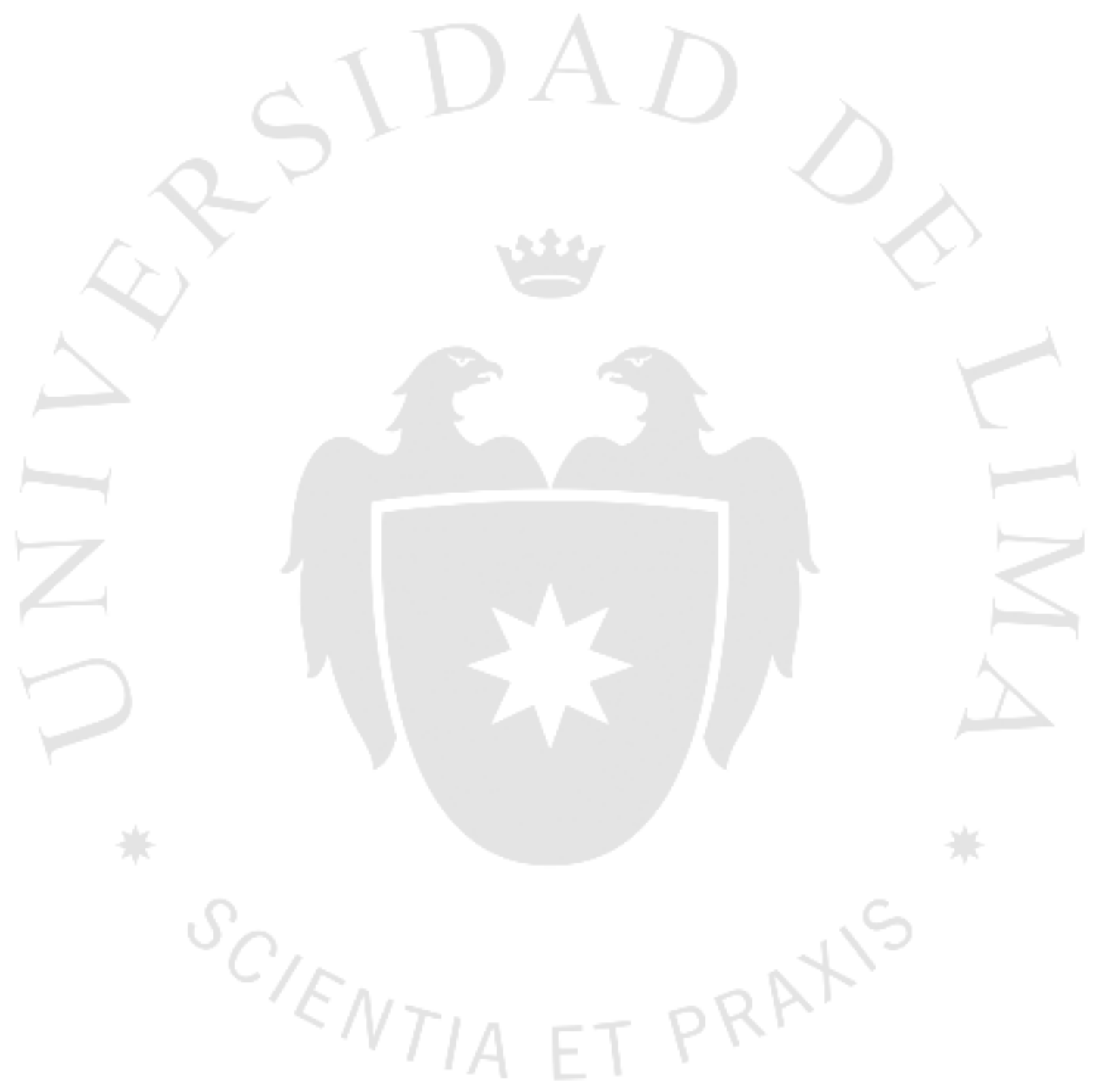




\section{REVISIÓN DEL ARBITRAJE POTESTATIVO COMO MECANISMO DE SOLUCIÓN DE CONFLICTOS LABORALES}




\section{TABLA DE CONTENIDO}

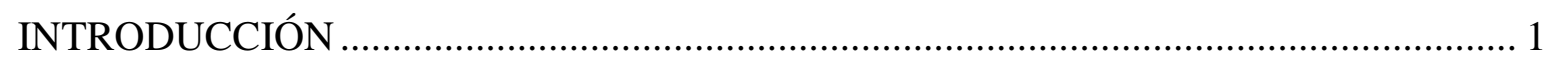

CAPÍTULO I: NEGOCIACIÓN COLECTIVA ................................................... 3

1.1 Conceptos relacionados a la negociación colectiva...................................... 3

1.1.1 Definición y clasificación de los conflicos laborales .................................. 3

1.1.2 El Convenio Colectivo desde la perspectiva de la OIT .............................. 4

1.2 Negociación Colectiva........................................................................... 5

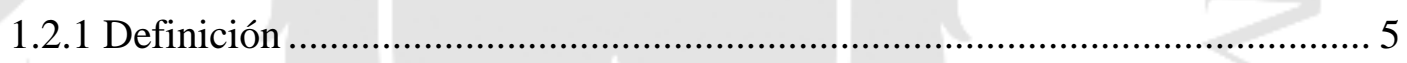

1.2.2 Etapas de la Negociación Colectiva ......................................................... 7

1.2.2.1 Primera Etapa: Negociación Directa .................................................... 7

1.2.2.2 Segunda Etapa: Conciliación............................................................ 10

1.2.2.3 Tercera Etapa: Arbitraje......................................11

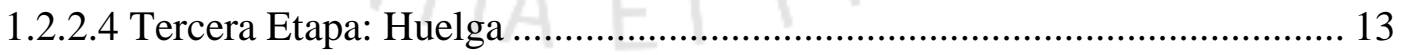

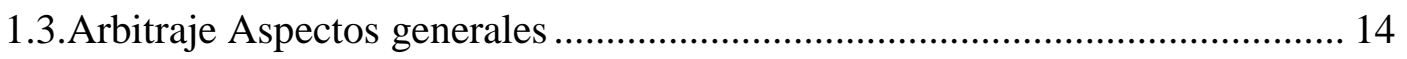

1.3.1 Concepto de arbitraje ....................................................................... 14

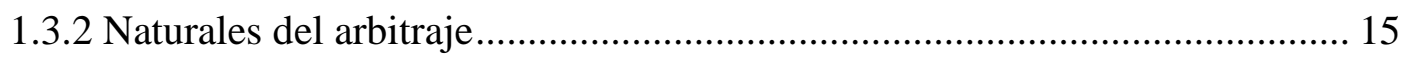




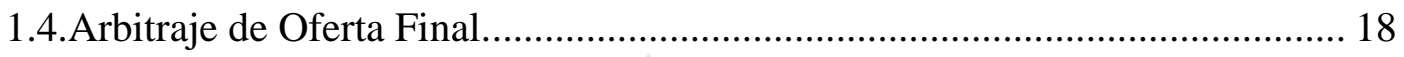

\section{CAPÍTULO II: ARBITRAJE POTESTATIVO_................................................................ 21}

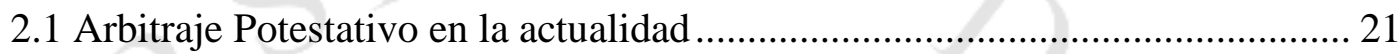

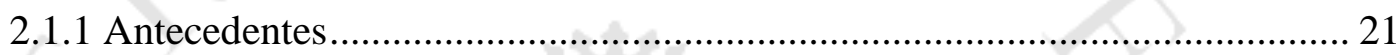

2.1.2 Setencia del Tribunal Constitucional relacionadas a la aplicación del

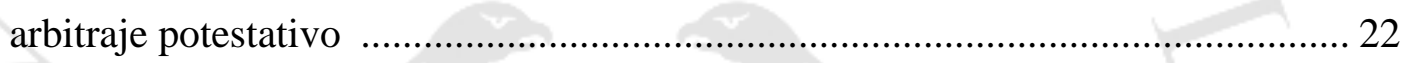

2.1.2.1 Sentencia del Tribunal Constitucional recíada en el Expediente $\mathrm{N}^{\circ} 03561$ 2009-PA/TC

2.1.2.2 Sentencia Aclaratoria del Tribunal Constitucional recaída en el Expediente

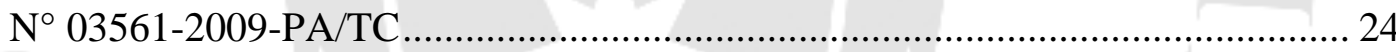

2.1.3 Modificación del Reglamento de la Ley de Relaciones Colectivas de

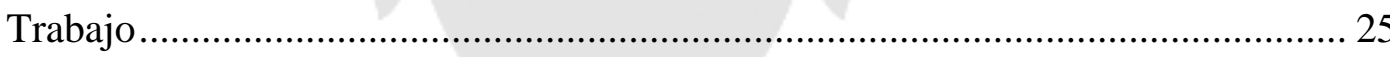

2.1.4 Resolución Ministerial N 284-2011-TR .................................................... 29

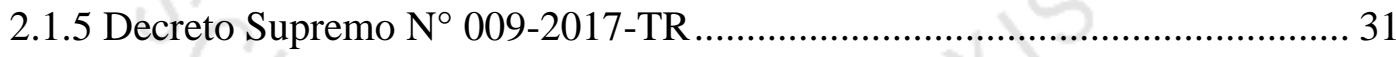

2.1.6 Procedimiento del Arbitraje Potestativo …………....................................... 36

2.1.6.1 Designación de arbitros por las partes ........................................................ 36

2.1.6.2 Designación de arbitros por la Autoridad Administrativa de Trabajo......... 36

2.1.6.3 Requisitos para ser árbitro ¡Error! Marcador no definido.36

2.1.6.4 Sustitución de los árbitros ¡Error! Marcador no definido. 37 
2.1.6.5 Presentación de propuestas por las partes ¡Error! Marcador no definido. 37

2.1.6.6 Etapa de actuaciones ¡Error! Marcador no definido. 37

2.2 Críticas al arbitraje potestativo 38

2.2.1 Vulneración al Principio de Jerarquía Normativa 38

2.2.2 La ilegal obligatoriedad del arbitraje potestativo 41

2.2.3 La designación de los árbitros 44

2.2.4 La mala fe como causal de arbitraje potestativo. 45

2.2.4.1 Causales de la mala fe y observaciones a la instancia que evalúa su configuración 46

2.2.4.2 En relación a los criterios utilizados para determinar la mala fe. 48

2.2.5 El arbitraje potestativo en empresas estatales 51

2.2.6 La eventual declaratoria de insconstitucionalidad del Decreto Supremo $\mathrm{N}^{\circ}$

014-2011-TR 54

2.3 Problemas en la aplicación del arbitraje potestativo 56

2.3.1 El arbitraje potestativo incausado. 56

2.3.2 La desnaturalización del arbitraje de opción ..... 58

\section{CAPÍTULO III: SOLUCIONES A LOS PROBLEMAS DE APLICACIÓN DEL} ARBITRAJE POTESTATIVO

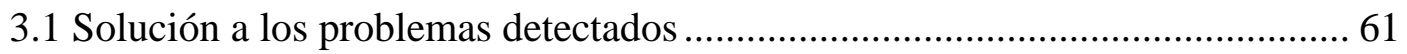

3.1.1 En relación a la vulneración del principio de prelación normativa ............... 61

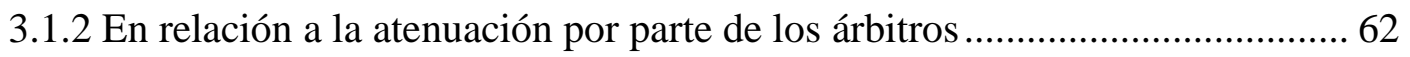


3.1.3 En relación al arbitraje potestativo incausado

3.2 Proyecto de Ley que subsana los problemas detectados 67

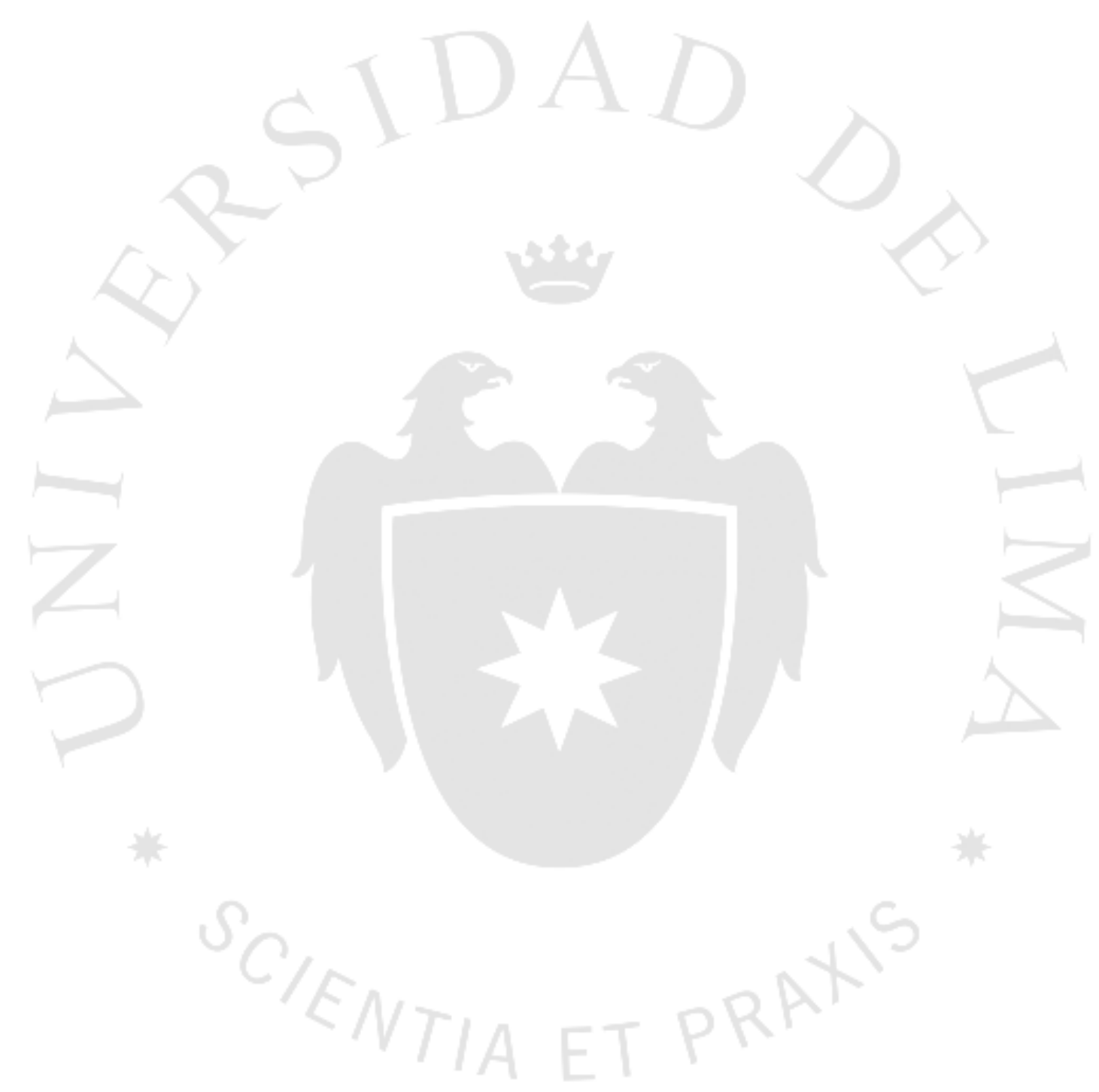




\section{INTRODUCCIÓN}

La permanente transformación del arbitraje potestativo, tanto en su composición como en ejecución, hace que su estudio importe un debate y análisis transcendente dentro del marco regulatorio laboral. En efecto, si bien de manera iniciática, la configuración del arbitraje potestativo comenzó con una sentencia del Tribunal Constitucional Peruano y regulaciones provenientes de la Autoridad Administrativa de Trabajo acatando dicha sentencia, en la actualidad son los laudos arbitrales, a través de disimiles razonamientos, los que han promovido que dicho mecanismo varíe de criterios.

El acudir a cualquier arbitraje representa, en líneas generales, declinar a la posibilidad de mantener el control respecto del resultado final de una negociación colectiva, es decir, sobre el contenido del convenio colectivo.

A siete años de la entrada de vigencia del arbitraje potestativo, creemos que el factor predominante que ha repercutido en la proliferación de este tipo de mecanismo alternativo de solución de conflictos, radica esencialmente a que con anterioridad a la dación del Decreto $\mathrm{N}^{\circ}$ 014-2011-TR, la ejecución de una medida de fuerza válida por parte de los trabajadores no generaba en los empleadores suficientes incentivos para negociar de manera rápida o cerrar el conflicto a través de un convenio colectivo. Lo señalado se agudizaba de manera exponencial, cuando las agrupaciones gremiales no se constituían como una "población relevante" dentro de las empresas, lo que promovía que las empresas optaran por negociar "despacio" a fin de desgastar a la contraparte quien a su vez tiene la presión de un resultado inmediato. 
Conforme a lo señalado, y estando que este mecanismo desde la dación del Decreto $\mathrm{N}^{\circ}$ 014-2011-TR supone una alternativa - bajo los parámetros sindicales- más efectiva que el procedimiento regular de una negociación colectiva, creemos que resulta necesario profundizar los aspectos novedosos de este tipo de arbitraje, así como analizar sus principales críticas y alternativas de solución.

En el presente trabajo analizaremos y comentaremos, a través del desarrollo de tres capítulos, los principales aspectos del nuevo enfoque del Tribunal Constitucional, concordándolos con los pronunciamientos previos sobre la materia, los aspectos más relevantes de las críticas al arbitraje potestativo desde una perspectiva constitucional, y finalmente, en un tercer capítulo, presentar las soluciones planteada.

A manera de conclusión adelantada, consideramos que el arbitraje potestativo ha cambiado las reglas de las negociaciones colectivas en el Perú, y en tanto su marco normativo no se alinee con los preceptos constitucionales vigentes, su aplicación resultaría deficiente y poco comprensible. 


\section{CAPÍTULO I:}

\section{LA NEGOCIACIÓN COLECTIVA}

\subsection{CONCEPTOS RELACIONADOS A LA NEGOCIACIÓN COLECTIVA}

A efectos de definir el correcto alcance de lo que una negociación colectiva sugiere, es imprescindible analizar algunos conceptos previos que permitirán abordar este punto desde una perspectiva sistémica. En tal sentido, consideramos adecuado iniciar el desarrollo del presente trabajo detallando los siguientes aspectos:

\subsubsection{DEFINICIÓN Y CLASIFICACIÓN DE LOS CONFLICTOS LABORALES}

Los conflictos laborales pueden ser definidos como aquellas controversias que se suscitan entre empleadores y trabajadores a consecuencia de la prestación del servicio que este último realiza. Según Krotoschin, el conflicto laboral puede ser conceptualizado como "aquella controversia de cualquier clase, que nace de una relación de derecho laboral entre un trabajador y un empleador, entre varios trabajadores, entre grupos de empleadores y trabajadores y entre cualquiera de éstos, por una parte, y el Estado, por la otra." 1

Los conflictos laborales pueden dividirse en:

- Conflictos individuales, cuando se constituyen a consecuencia de una o más personas específicas;

\footnotetext{
${ }^{1}$ KROTOSCHIN Ernesto. Instituciones del derecho del trabajo, $2^{\circ}$ ed. Buenos Aires, 1968. P. 602
} 
- Conflictos colectivos, referidos a un conjunto determinado de trabajadores que tienen un interés común;

- Conflictos de derecho, cuando versan sobre la interpretación de un derecho nacido y actual o de la aplicación de un convenio colectivo o laudo;

- Conflictos de interés, cuando se pretende modificar un derecho existente o crear uno nuevo.

Conforme a lo señalado en la parte introductoria del presente trabajo, la tesis propuesta enfoca su atención en los conflictos laborales colectivos, siendo este particular conflicto el que de manera directa repercute en el arbitraje materia de análisis.

En esta misma línea, Palomeque López señala que la noción de conflicto colectivo reposa en un doble elemento: i) la existencia de una pluralidad de sujetos en la posición jurídica de los trabajadores en conflicto y ii) un interés colectivo esgrimido por los trabajadores en la controversia. ${ }^{2}$

De lo precisado, consideramos entonces que los conflictos colectivos son definidos como una controversia cuyo contenido afecta a las relaciones de trabajo y repercute en forma indiferenciada sobre una colectividad de trabajadores.

\subsubsection{EL CONVENIO COLECTIVO DESDE LA PERSPECTIVA DE ORGANIZACIÓN INTERNACIONAL DE TRABAJO (OIT)}

El convenio colectivo, bajo los alcances de la OIT, ha sido motivo de estudio a través de innumerables normas que regulan su ámbito; sin embargo, de manera consensuada a

\footnotetext{
${ }^{2}$ PALOMEQUE LOPEZ Manuel Carlos. Derecho del Trabajo.
} 
través de diversas recomendaciones, se puede definir a esta figura como el proceso a través del cual las partes de un conflicto laboral, previa fase de negociación colectiva, se obligan al cumplimiento de un acuerdo formal. Sobre el particular, la OIT en su Recomendación $\mathrm{N}^{\circ}$ 91 ha definido al convenio colectivo como:

"todo acuerdo escrito relativo a las condiciones de trabajo y de empleo, celebrado entre un empleador, un grupo de empleadores o una o varias organizaciones de empleadores, por una parte, y, por otra, una o varias organizaciones representativas de trabajadores o, en ausencia de tales organizaciones, representantes de los trabajadores interesados, debidamente elegidos y autorizados por estos últimos, de acuerdo con la legislación nacional”.

De lo señalado, consideramos que el Convenio Colectivo comprende todo acuerdo escrito relativo a las condiciones de trabajo y de empleo, celebrado entre un empleador y una o varias organizaciones representativas de trabajadores. Una particularidad de ello, es que este acuerdo formal reviste un carácter vinculante importando su primacía sobre los contratos de trabajo individual que se hayan suscrito con anterioridad o posterioridad a entrada en vigencia del convenio, con la única salvedad de garantizar las disposiciones más beneficiosas para los trabajadores

\subsection{LA NEGOCIACIÓN COLECTIVA}

\subsubsection{Definición}

Bajo los alcances del artículo $28^{\circ}$ de la Constitución Política del Perú, el Estado reconoce los derechos de sindicación, negociación colectiva y huelga, cautelando su 
ejercicio democrático a través, dentro de otros aspectos, del fomento de la negociación colectiva y la promoción formas de solución pacífica de los conflictos laborales.

La negociación colectiva, conforme a los preceptos constitucionales antes señalados, tiene fuerza vinculante en el ámbito de lo concertado y fundamenta su existencia en la promoción de espacios de diálogo en donde trabajadores y empleadores pacten el plazo de validez de la negociación, constituyendo este mecanismo una solución pacífica de eventuales conflictos laborales.

En tal sentido, Jorge Rendón Vásquez señala que "la negociación colectiva es un procedimiento laboral por el cual los trabajadores pueden plantear aumentos de remuneraciones, la fijación de remuneraciones mínimas, la modificación de las condiciones de trabajo y la creación de cualquier otro derecho de carácter social, para llegar a una convención colectiva". ${ }^{3}$

En esa misma línea, Osvaldino Rojas Lugo, precisa que la negación colectiva “constituye un conjunto de discusiones, transacciones y acuerdos, mediante los cuales un patrono sea este persona natural o jurídica, y un grupo o asociación de empleados, o una organización sindical representativa de los intereses del grupo de trabajadores, libremente establecen las normas y condiciones a las cuales se ajustarán las relaciones entre ambos, conforme a un procedimiento pacífico que posibilite el progreso general de la comunidad jurídicamente organizada y la más equitativa distribución de las riquezas dentro del medio de producción". ${ }^{4}$

\footnotetext{
${ }^{3}$ RENDÓN VÁSQUEZ, Jorge. Derecho del Trabajo Colectivo. Quinta Ed. Edit. Edial. Octubre 1998. P. 218

${ }^{4}$ ROJAS LUGO, Osvaldino. El Desarrollo del Derecho Laboral en Puerto Rico e Iberoamérica y su Interrelación con el Desarrollo Político. Impreso en Puerto Rico por RAMALLO Bros. Printing, INC. 1997. P. 57
} 
Desde una perspectiva supranacional la OIT, a través del artículo $4^{\circ}$ de su Convenio 98, precisa y recomienda en relación a la negociación colectiva, la adopción de "medidas adecuadas a las condiciones nacionales, cuando ello sea necesario, para estimular y fomentar entre los empleadores y las organizaciones de empleadores, por una parte; y las organizaciones de trabajadores, por otra, el pleno desarrollo y uso de procedimientos de negociación voluntaria, con objeto de reglamentar, por medio de contratos colectivos, las condiciones de empleo".

Conforme a lo señalado, consideramos que la negociación colectiva implica un conjunto de actos previos que buscan, a través de concesiones mutuas, la celebración de la Convención Colectiva de Trabajo. Este proceso, debidamente fomentado por el Estado, debe permitir a los "contendientes" intercambiar promesas y contraer compromisos formales para la solución de sus diferendos y consecuentemente, arribar a un equitativo acuerdo formal de trabajo. ${ }^{5}$

\subsubsection{Etapas de la Negociación Colectiva}

\subsubsection{Primera Etapa: Negociación Directa}

En esta etapa inicial, las partes proceden a discutir sobre el pliego de reclamos presentado, dicha reunión se puede dar en el centro de trabajo u otro cualquier lugar sin la presencia de las Autoridades de Trabajo.

El pliego de reclamos es constituido por un documento que contiene los puntos de petición de la organización sindical, o de los trabajadores reunidos, presentada a los

\footnotetext{
${ }^{5}$ DIAZ AROCO Teófila T. Derecho Colectivo del Trabajo. Lima, agosto del 2011. P. 409
} 
empleadores. Dicho documento sirve como base para una posible solución ante las autoridades de trabajo o arbitrales.

Conforme a lo señalado en artículo $51^{\circ}$ de la Ley de Relaciones Colectivas de Trabajo, la negociación colectiva se inicia con la presentación de un pliego que debe contener un proyecto de convención colectiva, con lo siguiente:

a) Denominación y número de registro del o de los sindicatos que lo suscriben, y domicilio único que señalen para efectos de las notificaciones. De no existir sindicato, las indicaciones que permitan identificar a la coalición de trabajadores que lo presenta.

b) La nómina de los integrantes de la comisión negociadora con los requisitos establecidos por el artículo 49.

c) Nombre o denominación social y domicilio de cada una de las empresas u organizaciones de empleadores comprendidas.

d) Las peticiones que se formulan sobre remuneraciones, condiciones de trabajo y productividad y demás que se planteen, las que deberán tener forma de cláusula e integrarse armónicamente dentro de un solo proyecto de convención.

e) Firma de los dirigentes sindicales designados para tal fin por la asamblea, o de los representantes acreditados, de no haber sindicato.

El pliego de reclamos será presentado directamente a la empresa con copia para la Autoridad de Trabajo respectiva. Si la empresa se negará a recibirlo, la entrega se hará mediante la Autoridad de Trabajo y su fecha de presentación es el día que ingreso a la mesa de partes de la Autoridad de Trabajo. 
Asimismo, debe tenerse en consideración que el pliego de reclamos deberá presentarse no antes de sesenta días ni después de treinta días calendarios anteriores a la fecha de terminación del periodo negocial en curso. En caso de presentarse por primera vez, se puede hacer en cualquier momento, luego de transcurrido el primer año de funcionamiento de la empresa.

Una vez recibido el pliego de reclamos, el empleador, los empleadores o la organización de empleadores, en acuerdo con la organización sindical, deben señalar fecha y hora para dar inicio a las reuniones. Sobre el particular, el artículo $57^{\circ}$ de la Ley de Relaciones Colectivas de Trabajo, señala que la negociación colectiva se realizará en los plazos y oportunidades que las partes acuerden, dentro o fuera de la jornada laboral, y debe iniciarse dentro de los diez (10) días calendario de presentado el pliego.

Otro aspecto a tomar en consideración, radica en el hecho de que los empleadores u organización de empleadores, están obligados a asistir a las reuniones de negociación directa. Si estos no pudieran, la organización sindical podría reiterar su pedido de citación, bajo apercibimiento de dar por terminado esta primera etapa.

Ahora bien, al reunirse las partes por primera vez, se podrá designar un presidente que llevará la dirección del debate, cargo que puede alternarse en un representante de los trabajadores en una reunión y en otra, por un representante de los empleadores.

En la negociación directa no existe un plazo legal de duración y se podría dar cuantas reuniones deseen las partes. Durante las negociaciones directas existen algunas reglas que deben ser observadas:

a) El empleador puede proponer cláusulas nuevas o sustitutorias de las establecidas en convenciones anteriores. 
b) Obligación de los empleadores de informar a petición de los representantes de los trabajadores, la información sobre la situación económica, financiera, social y demás pertinentes de la empresa.

c) Las partes deberán negociar de buena fe y a abstenerse de toda acción que pueda ser lesiva a la contraria.

d) El desarrollo del pliego de reclamos se debe realizar en el orden de sus puntos o tratando primero algunos de ellos.

En caso de llegar a un acuerdo, se levanta un acta que es suscrita por las partes en triplicado, y un ejemplar es remitido a la Autoridad de Trabajo, debiendo las partes informar a la Autoridad de Trabajo de la finalización de la etapa de negociación directa para poder solicitar el inicio de un procedimiento de conciliación. En el caso que ninguna de las partes lo solicitara, la Autoridad de Trabajo podrá iniciarlo de oficio según sea el caso.

\subsubsection{Segunda Etapa: Conciliación}

En esta estadía, se constituye una junta de conciliación que es presidida por un conciliador designado por el subdirector de negociaciones colectivas, o por una persona designada por las partes. La razón de ser de esta etapa, radica en buscar que las partes prosigan con la discusión de los puntos del pliego pendiente de solución, asistidas por un funcionario u otra persona que dirija el debate.

Conforme a lo señalado en el artículo $59^{\circ}$ de la Ley de Relaciones Colectivas de Trabajo, la función conciliatoria estará a cargo de un cuerpo técnico especializado y calificado del Ministerio de Trabajo y Promoción del Empleo. De esta manera, las partes, si 
así lo acuerdan, podrán encomendársela a personas privadas; en este caso, deberán remitir a la Autoridad de Trabajo una copia de las actas que se levanten. En uno y otro caso, el procedimiento de conciliación deberá caracterizarse por la flexibilidad y la simplicidad en su desarrollo, debiendo desempeñar un papel activo en la promoción del avenimiento entre las partes. Si estas lo autorizan, el conciliador podrá actuar como mediador, a cuyo efecto, en el momento que lo considere oportuno, presentará una o más propuestas de solución que las partes pueden aceptar o rechazar. Se realizarán tantas reuniones de conciliación como sean necesarias. En el caso de ser agotada esta etapa, las partes podrán continuar con las conversaciones directamente para resolver el conflicto y evitar la siguiente etapa que sería el arbitraje.

\subsubsection{Tercera Etapa: Arbitraje}

La obligatoriedad de esta etapa al no haber acuerdo de partes, surge de la Constitución, ya que esta dispone que los conflictos derivados de la relación contractual solo se solucionen en la vía arbitral o en la judicial.

La Ley de Relaciones Colectivas de Trabajo menciona que, si no se hubiese llegado a un acuerdo en negociación directa o en conciliación, de haberla solicitado los trabajadores, podrán las partes someter el diferendo a arbitraje, salvo que los trabajadores opten por ejercer alternativamente el derecho de huelga.

En el desarrollo de la huelga, los trabajadores podrán proponer el sometimiento del conflicto a arbitraje, pero con la aceptación del empleador.

Las partes, asimismo, pueden fijar aspectos puntuales de discrepancia respecto a los cuales debe pronunciarse el árbitro, siempre y cuando sea de común acuerdo; de no darse 
esta situación, la decisión arbitral debe ser de los puntos a los que no se llegó a un acuerdo durante la negociación directa.

Según lo establecido el artículo $49^{\circ}$ del Reglamento de la Ley de Relaciones Colectivas de Trabajo, la decisión de someter la controversia a arbitraje constará en un acta denominada "compromiso arbitral", que contendrá el nombre de las partes, los de sus representantes y sus domicilios, modalidad de arbitraje, información sobre la negociación colectiva que se somete a arbitraje, monto y forma de pago de las costas y honorarios de los árbitros, lugar de arbitraje y facilidades para el funcionamiento del Tribunal.

Las partes que suscribieron el compromiso arbitral, deberán designar sus árbitros en un plazo no mayor de 5 días hábiles; de no hacerlo una de ellas, la Autoridad Administrativa de Trabajo designará al árbitro correspondiente, cuyo costo asumirá la parte responsable de su designación. Si por alguna circunstancia cualquiera de los árbitros dejara de asistir o renunciara, la parte afectada deberá sustituirlo en el término no mayor de tres días hábiles. En caso de no hacerlo, el Presidente del Tribunal solicitará a la Autoridad Administrativa de Trabajo su sustitución.

El arbitraje puede ser de un árbitro unipersonal, un tribunal ad-hoc, una institución representativa, la Autoridad de Trabajo o cualquier otra modalidad que las partes acuerden, si no existirá un acuerdo del órgano arbitral se constituirá de oficio un tribunal tripartito. En ningún caso podrán ser árbitros los abogados, asesores, representantes, apoderados o, en general, las personas que tengan relación con las partes o interés, directo o indirecto, en el resultado.

La intervención de la Autoridad de Trabajo se da para imponer la vía arbitral y para nombrar a los árbitros si las partes no lo hacen. 
En relación al laudo arbitral que se emita, cabe precisar que, sin importar la modalidad del órgano arbitral, su laudo es inapelable y tiene carácter imperativo para las partes, siendo el caso que ante un eventual error material, numérico, de cálculo, tipográficos o de naturaleza similar, cualquiera de las partes o de oficio podrá solicitar, dentro del siguiente día hábil posterior a la notificación, su subsanación.

Finalmente, cabe señalar que el laudo arbitral puede ser susceptible de impugnación ante la Sala Laboral de la Corte Superior, únicamente por los siguientes motivos:

a) Por razón de nulidad.

b) Por establecer menores derechos a los contemplados en favor de los trabajadores.

Si la Autoridad de Trabajo decide resolver una negociación colectiva en última instancia, dicha decisión no puede ser sometida a la acción de nulidad. La acción impugnatoria que puede presentar alguna de las partes, no posterga de ninguna manera la ejecución del laudo arbitral, salvo resolución contraria de la autoridad judicial competente.

\subsubsection{Tercera Etapa: Huelga}

De no ir por la vía arbitral, los trabajadores pueden alternativamente declarar la huelga, en cuyo caso las partes o Autoridad de Trabajo designarán a un mediador.

La huelga viene a ser una suspensión colectiva del trabajo aprobada mayoritariamente y de forma voluntaria por los trabajadores de una empresa, donde se produce el abandono del centro de labores. 
La norma legal no fija para esta etapa un plazo de duración determinada, por lo cual, podría durar todo el tiempo que los trabajadores y empleadores soporten hasta llegar a un acuerdo.

\subsection{EL ARBITRAJE. ASPECTOS GENERALES}

1.3.1. Concepto de arbitraje

Conforme a la recurrente doctrina nacional, arbitraje es definido como un procedimiento a través del cual una controversia es sometida, por acuerdo de partes, a un tercero a efectos este, a través de una decisión motivada, resuelva de manera definitiva la controversia y ejecute su decisión vinculante, generando efectos inter partes.

Sobre el particular, Rodríguez Roblero, señala que el arbitraje es definido “como aquella institución jurídica por la cual los litigios, basados en la voluntad de las partes, son sustraídos a la justicia estatal para ser resueltos por individuos revestidos de la potestad para juzgarlos ${ }^{, 6}$.

Se puede desprender de lo ante mencionado, que es necesario para configurar un arbitraje que primero exista un acuerdo de voluntades por el cual dos o más personas deciden someter a un tercero la solución de un determinado conflicto; y segundo, las partes deben tener facultad para poder disponer libremente de sus derechos.

La Constitución menciona a los tribunales estatales como un medio de solución de conflictos que se susciten entre particulares, o entre particulares y el Estado; también permite ir por una vía arbitral. En tal sentido, la Constitución Política del Perú, a través de

\footnotetext{
6 RODRIGUEZ ROBLERO María Inmaculada. Impugnación de acuerdos sociales y arbitrajes. Tesis Doctoral. Universidad Complutense de Madrid. Madrid, Noviembre de 2009. P. 26
} 
sus artículos $138^{\circ}$ y $139^{\circ}$, precisa que "la potestad de administrar justicia emana del pueblo y se ejerce por el Poder Judicial a través de sus órganos jerárquicos con arreglo a la Constitución y a las leyes", señalando además que "no existe ni puede establecer jurisdicción alguna independiente, con excepción de la militar y la arbitral”.

1.3.2. Naturaleza del arbitraje

Para poder analizar de manera correcta la naturaleza del arbitraje, la doctrina ha desarrollado cuatro teorías relevantes: la teoría jurisdiccional, la contractual, la mixta y la autónoma.

La teoría jurisdiccional se fundamenta en el hecho de que el arbitraje, en esencia, comparte la misma naturaleza que la función jurisdiccional. Esta vertiente señala que el Estado debe "normar" los arbitrajes dentro de su jurisdicción de manera soberana, dado que la solución de controversias por parte de este mecanismo nace de un acto de justicia delegada, hecho que materializado en la ejecución de sus decisiones (laudos) comparte en esencia la misma fuerza ejecutiva de una sentencia judicial.

La teoría contractual postula que el arbitraje, conforme a sus orígenes y regulación, obedece y existe en tanto permanezca en la voluntad de las partes. El fundamento principal de esta vertiente, consiste en que el proceso arbitral nace y se regula de un acuerdo contractual, fundamentando su esencia en la autonomía de la voluntad que dio origen a dicho sistema de justicia. Esta posición niega la preponderancia y/o control del Estado sobre el arbitraje. 
La teoría mixta o híbrida, nace antes los cuestionamientos a las vertientes anteriores (jurisdiccional y contractual). En tal sentido, esta posición precisa que en el arbitraje no existe acto de delegación jurisdiccional por parte del Estado, siendo el caso que si bien las funciones arbitrales pueden ser equiparadas a las de un juez, esto se encuentra limitado únicamente al caso concreto, puesto que mientras el magistrado está investido en de poder público estatal, la decisiones de un árbitro no cuentan con dicho poder público. ${ }^{7}$

Finalmente, la teoría autónoma es una versión perfeccionada de la teoría mixta. Esta vertiente precisa que el arbitraje se desenvuelve en una categorización independiente y por tanto autónoma, que no podría ser clasificada como jurisdiccional ni como contractual. La teoría autónoma reconoce los elementos jurisdiccionales y contractuales del arbitraje, pero enfatiza su atención en el medio legal y empresarial donde las partes acuerdan a someter el procedimiento arbitral.

De lo señalado, consideramos que, al margen de los fundamentos precitados, no resulta relevante para este trabajo abundar sobre las aristas que diferencian cada una de estas corrientes; por lo contrario, consideramos que el objeto de señalar cada una de estas teorías es establecer, como patrón común, que el arbitraje como instancia autónoma cuenta en la legislación nacional con fuerza coercitiva suficiente para ejecutar sus mandatos.

1.3.3. Tipos de arbitraje

El arbitraje, conforme a la naturaleza de la controversia que pretenda resolver, puede ser clasificado de diversas formas.

\footnotetext{
${ }^{7}$ Como fue reconocido en un caso ante la Corte de Justicia Europea (Caso Nordsee v. Reederei, Sentencia del 23 de marzo de 1982) en donde se sostuvo que únicamente las cortes estatales ejercen poder estatal.
} 
La clasificación de este mecanismo alternativo podrá variar (o complementarse) según la composición de sus árbitros, cuando estos son de equidad o derecho, según su jurisdicción, cuando estos sean nacionales o internacionales, según la administración del arbitraje, cuando estos son Ad Hoc o Institucional, o según la voluntad de las partes, cuando estos se constituyan voluntarios u obligatorios.

Para efectos del presente trabajo, no ahondaremos en todas las clasificaciones antes mencionadas, siendo relevante para circunscribir el marco legal del arbitraje materia estudio únicamente los arbitrajes clasificados bajo la voluntad de las partes y los vinculados a la composición de sus árbitros.

1.3.3.1. Según la voluntad de las partes, los arbitrajes pueden ser:

\section{a) Arbitraje Voluntario}

Es aquel arbitraje por el cual las partes deciden voluntariamente someter su conflicto de intereses a un tercero, denominado "arbitro" o "tribunal arbitral", para que a través de ellos puedan dar solución a la controversia que pudiera suscitarse. Si las partes deciden este tipo de arbitraje, deberían suscribir un compromiso arbitral.

b) Arbitraje obligatorio

Este tipo de arbitraje radica en la inexistencia de voluntariedad, y se da porque existen determinados bienes jurídicos que son superiores a los intereses de los sindicatos y de las empresas. Un claro ejemplo, sería que los trabajadores de suministro de agua realicen una huelga, eso repercutiría gravemente a la sociedad. 
1.3.3.2. Según la composición de sus árbitros, los arbitrajes pueden constituirse como:

a) Arbitraje de Derecho

Es aquel arbitraje por el cual se debe aplicar obligatoriamente criterios y reglas jurídicas y únicamente los profesionales en derecho pueden optar la condición de árbitros bajo sanción de nulidad.

b) Arbitraje de Equidad

Es aquel arbitraje donde el conflicto se decide por la justicia natural y el sentimiento del deber de equidad. Los árbitros no necesariamente tienen que ser profesionales de derecho y deben de laudar circunscribiendo su criterio su concreto real entender y saber.

\subsection{EL ARBITRAJE DE OFERTA FINAL}

En este modelo arbitral, más allá de las reglas que regulan su procedimiento, lo fundamental es que las partes del proceso presenten ante el tribunal su propuesta final a efectos de que este órgano colegiado elija, en base a criterios de equidad y justicia, cual posición resulta adecuada para resolver la materia controvertida.

Este sistema busca contrarrestar el afán que tienen las organizaciones sindicales y las empresas de acudir rápidamente al arbitraje cuando tienen problemas en las negociaciones directas o conciliación. En tal sentido, al optar íntegramente el tribunal arbitral por alguna de las propuestas señaladas por las partes, este arbitraje busca generar duda (en los contendientes) respecto del resultado que tendrá el laudo arbitral, en tanto el Tribunal Arbitral, al no poder modificar las propuestas presentadas por puntos intermedios, 
promoverá indirectamente que las partes opten por soluciones consensuadas en desmedro de un sistema "gana o pierde".

Conforme a lo señalado en el primer párrafo del artículo $65^{\circ}$ de la Ley de Relaciones Colectivas de Trabajo, nuestra legislación ha adoptado el sistema de "Oferta Final", al señalar que "el laudo no podrá establecer una solución distinta a las propuestas finales de las partes ni combinar planteamientos de una y otra. El laudo recogerá en su integridad la propuesta final de una de las partes".

Sin embargo, y contrario al sentido de lo antes señalado, el segundo párrafo del mismo artículo señala que tribunal arbitral "podrá atenuar posiciones extremas". Esto último desvirtúa tanto el sistema como los objetivos del arbitraje de oferta final.

Conforme a lo señalado, y lejos de circunscribir sus efectos a un arbitraje de oferta final puro, dentro de la casuística arbitral nacional se tienen tres modalidades de arbitraje de "Oferta Final":

a) Elección entre dos propuestas

Es el modelo base (y puro) puesto que aquí, el tribunal arbitral escoge una de las dos propuestas finales presentadas por las partes. En esta modalidad, las partes en la primera propuesta arriesgan todo.

Nuestra legislación peruana acoge este sistema y lo plasma en el artículo $65^{\circ}$ de la Ley de Relaciones Colectivas de Trabajo

b) Elección de la propuesta dosificada 
En esta modalidad, las partes presentan su oferta final y el árbitro tiene la facultad de “dosificar” las propuestas recibidas y llevar a una propuesta general más equilibrada y justa. Como ya se mencionó previamente, nuestra legislación acoge este sistema distorsionado y permite atenuar la propuesta elegida.

c) Modalidad intermedia

En este modelo, las partes presentan cada una de ellas dos propuestas, es decir, hay cuatro propuestas finales. Aquí el tribunal arbitral elige entre ellas y de esta manera reduce la disconformidad que pueda tener la otra parte.

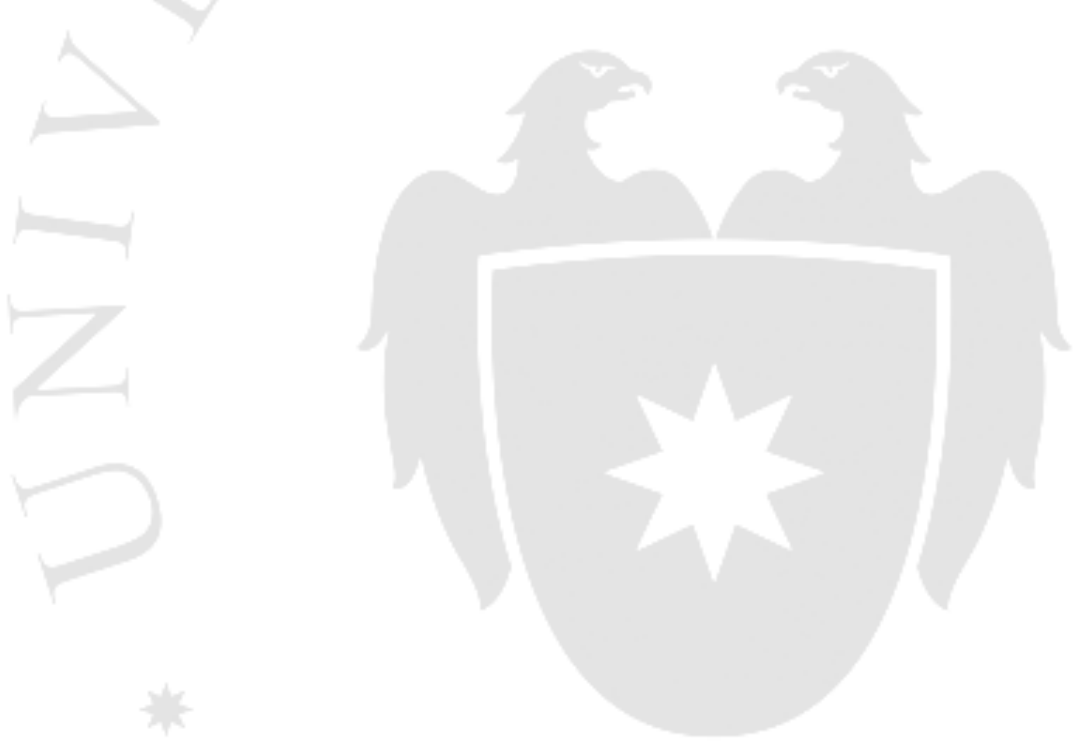




\section{CAPÍTULO II}

\section{EL ARBITRAJE POTESTATIVO}

\subsection{EL ARBITRAJE POTESTATIVO EN LA ACTUALIDAD}

\subsubsection{ANTECEDENTES}

La figura del arbitraje en temas de negociación colectiva, ha sido recogida inicialmente en la Ley $\mathrm{N}^{\circ}$ 25593, Ley de Relaciones Colectivas de Trabajo, específicamente en su artículo $61^{\circ}$ al sostener que "si no se hubiese llegado a un acuerdo en negociación directa o en conciliación, de haberla solicitado los trabajadores, podrán las partes someter el diferendo a arbitraje”. En ese mismo sentido, el artículo $63^{\circ}$ de la misma norma, refiere que si "durante el desarrollo de la huelga los trabajadores podrán, asimismo, proponer el sometimiento del diferendo a arbitraje, en cuyo caso se requerirá de la aceptación del empleador”.

Posteriormente, el artículo $46^{\circ}$ del Reglamento de la Ley de Relaciones Colectivas de Trabajo, aprobado por Decreto Supremo N 011-92-TR y modificado por Decreto Supremo N 009-93-TR, señaló que "si al término de la negociación directa, o de la conciliación, de ser el caso, según el artículo $61^{\circ}$ de la Ley, cualquiera de las partes podrá someter la decisión del diferendo a arbitraje, salvo que los trabajadores opten por ejercer alternativamente el derecho de huelga, de conformidad con el artículo 62 de la Ley”.

El arbitraje potestativo en negociación colectiva en nuestra legislación, se ha iniciado con la Sentencia del Tribunal Constitucional Expediente $\mathrm{N}^{\circ}$ 03561-2009-PA/TC y es mejor 
entendida con la Sentencia Aclaratoria del Tribunal Constitucional del 10 de junio del 2010.

El Decreto Supremo Nº14-2011-TR, donde se modifica el Decreto Supremo Nº 01192-TR y se crea el Registro Nacional de Árbitros de Negociaciones Colectivas, introduce el artículo $61^{\circ}$-A donde en donde por primera vez se menciona el arbitraje potestativo y su procedencia.

Finalmente, la Resolución Ministerial N²84-2011-TR, del 24 de setiembre del 2011, menciona los supuestos de mala fe en que pueda incurrir alguna de las partes.

\subsubsection{SENTENCIAS DEL TRIBUNAL CONSTITUCIONAL RELACIONADAS A LA} APLICACIÓN DEL AL ARBITRAJE POTESTATIVO

2.1.2.1 Sentencia del Tribunal Constitucional recaída en el Expediente $\mathrm{N}^{\circ}$ 03561-2009-PA/TC

Con fecha 29 de setiembre del 2009, el Tribunal Constitucional emite una resolución que, respecto de un proceso de amparo entre el Sindicato Único de Trabajadores Marítimos y Portuarios del Puerto de Callao, va contra diversas asociaciones de empleadores.

El Sindicato, con su demanda, pretende que se ordene el cumplimiento del Decreto $\mathrm{N}^{\circ}$ 447, de fecha 23 de noviembre de 2007, emitido por la División en el Exp. N 052-2007MTPE/2/12.710, que señala lo siguiente:

"Por recibido el expediente de Negociación Colectiva seguido entre el Sindicato Único de Trabajadores Marítimos y Portuarios del Puerto de Callao con Asociación 
Peruana de Agentes Marítimos, Asociación Peruana de Operadores Portuarios y Asociación Marítima del Perú: Estando a lo dispuesto por el Auto Directoral $N^{\circ} 037$ 2007-MTPE/2/12.7, de fecha 20 de noviembre de 2007, continúese con el procedimiento de negociación colectiva, en la etapa de Trato Directo”.

Por su parte, las asociaciones antes mencionadas señalan que el Sindicato no tiene derecho a negociar colectivamente por rama de actividad, sino a nivel empresa.

Sobre el particular, el Tribunal Constitucional concluyó en lo siguiente:

1) Declarar FUNDADA la demanda porque se ha acreditado la vulneración del derecho de negociación colectiva del Sindicato.

2) Declarar INAPLICABLE a las partes del presente proceso la segunda oración del primer párrafo del artículo $45^{\circ}$ del Decreto Supremo $N^{\circ}$ 010-2003-TR, cuyo texto dispone que: "a falta de acuerdo, la negociación se llevará a nivel empresa".

3) Ordenar a la Asociación Peruana de Agentes Marítimos, Asociación Peruana de Operadores Portuarios y Asociación Marítima del Perú que, en cumplimiento del Decreto $\mathrm{N}^{\circ}$ 447, asistan a las reuniones convocadas en el Exp. $\mathrm{N}^{\circ}$ 052-2007MTPE/2/12.710, debiéndose retrotraer el procedimiento de negociación colectiva hasta el momento anterior a la emisión del decreto referido.

4) Precisar que, a falta de acuerdo para decidir el nivel de negociación, este deberá ser determinado mediante el arbitraje, sin que exista previa declaración de huelga. 
De todos los numerales antes mencionados, el más resaltante es el numeral dos, ya que el Tribunal Constitucional se aleja de lo señalado en el artículo $45^{\circ}$ de la Ley de Relaciones Colectivas de Trabajo porque sería inconstitucional y estaría violando lo dispuesto en el artículo $28^{\circ}$ de la Constitución Política del Perú.

Asimismo, el Tribunal Constitucional estaría ejerciendo el famoso "control difuso", que está definido como aquella situación de conflicto de una norma legal frente a una norma constitucional en que se debe preferir esta última.

2.1.2.2 Sentencia Aclaratoria del Tribunal Constitucional recaída en el Expediente $\mathrm{N}^{\circ}$ 03561-2009$\mathrm{PA} / \mathrm{TC}$

Con fecha 10 de junio del 2010, el Tribunal Constitucional emitió una resolución aclaratoria que resolvió lo siguiente:

"Precisar que el arbitraje a través del cual deberá decidirse el nivel de la negociación ante la falta de acuerdo entre trabajadores y empleador, es aquél al que hace alusión el artículo $61^{\circ}$ del Decreto Supremo N. ${ }^{\circ}$ 010-2003-TR, el cual es de carácter potestativo. En tal sentido, sometido el diferendo a arbitraje por cualquiera de las partes, la otra tiene el deber de someterse a éste."

En este caso, el Tribunal Constitucional interpretó que cuando se den situaciones de mala fe que entorpecen o dilatan la solución de un conflicto, o que cuando las partes no se ponen de acuerdo en la primera negociación, se aplica el arbitraje potestativo.

Asimismo, en el considerado número 6 de la Resolución Aclaratoria, el Tribunal Constitucional señaló que el arbitraje laboral está compuesto por tres clases: 

a) Voluntario: las partes lo establecen de común acuerdo;
b) Potestativo: cuando una parte obliga a la otra para ir a arbitraje;
c) Obligatorio: cuando una tercera voluntad impone el arbitraje.

\subsubsection{MODIFICACIÓN DEL REGLAMENTO DE LA LEY DE RELACIONES COLECTIVAS DE TRABAJO}

Con fecha 16 de setiembre del 2011, se promulga el Decreto Supremo Nº 014-2011TR donde se creó un Registro Nacional de Árbitros de Negociaciones Colectivas que estará a cargo de la Dirección General de Trabajo del Ministerio de Trabajo y Promoción del Empleo, el que estará integrado por profesionales de reconocida trayectoria. Los requisitos específicos para la inscripción de árbitros son establecidos mediante resolución ministerial. Para actuar como árbitro en negociaciones colectivas de trabajo, conforme al decreto antes señalado, debe contarse con registro hábil del Registro Nacional de Árbitros de Negociaciones Colectivas. Cuando las normas sobre relaciones colectivas de trabajo dispongan que la Autoridad Administrativa de Trabajo deba designar un árbitro, o lo solicite una o ambas partes, esta competencia se entiende atribuida a la Dirección General del Trabajo.

Asimismo, en dicho cuerpo legal se agregó el artículo $61^{\circ}$ al Decreto Supremo $\mathrm{N}^{\circ} 011$ 92-TR, que fue redactado de la siguiente manera:

“Artículo 61-A.- Arbitraje potestativo 
Las partes tienen la facultad de interponer el arbitraje potestativo en los siguientes supuestos:

a) Las partes no se ponen de acuerdo en la primera negociación, en el nivel o su contenido; $\mathrm{y}$,

b) Cuando durante la negociación del pliego se adviertan actos de mala fe que tengan por efecto dilatar, entorpecer o evitar el logro de un acuerdo. “

Ocurridos los supuestos referidos, las partes deben designar a sus árbitros en un plazo no mayor de cinco (05) días hábiles. De no hacerlo una de ellas, la Autoridad Administrativa de Trabajo designa al árbitro correspondiente, cuyo costo asume la parte responsable de su designación. El arbitraje potestativo no requiere de la suscripción de un compromiso arbitral.

Si por alguna circunstancia alguno de los árbitros dejara de asistir o renunciara, el decreto en mención señala que la parte afectada deberá sustituirlo en el término no mayor de tres (03) días hábiles. En caso de no hacerlo, el presidente del tribunal solicita a la Autoridad Administrativa de Trabajo su sustitución.

Constituido el Tribunal Arbitral, dentro de los cinco (05) días hábiles siguientes, las partes entregan al tribunal su propuesta final, de ser el caso, en forma de proyecto de convenio colectivo, con copia para la otra parte, que le será entregado a este por el presidente del Tribunal Arbitral. 
Dentro de los cinco (05) días hábiles siguientes, las partes podrán formular al tribunal las observaciones debidamente sustentadas, que tuvieran respecto del proyecto de fórmula final presentado por la otra parte.

Resultan aplicables al arbitraje potestativo las reglas del procedimiento arbitral establecidas en el artículo $55^{\circ}, 56^{\circ}, 57^{\circ}, 58^{\circ}, 59^{\circ}, 60^{\circ}$ y $61^{\circ}$ del Reglamento. En el caso de la regla de integralidad establecida en el artículo $57^{\circ}$, esta no se aplicará cuando sólo exista una propuesta final presentada, pudiendo el Tribunal Arbitral establecer una solución final distinta. En ningún caso, el arbitraje potestativo puede ser utilizado en desmedro del derecho de huelga.

Del análisis del artículo antes señalado, se advierte que para la aplicación arbitraje potestativo, deben obrar dos causales:

a) Cuando las partes no se ponen de acuerdo en la primera negociación en el nivel o su contenido.

Para poder comprender mejor esta nueva causal, el artículo $44^{\circ}$ y $45^{\circ}$ del Texto Único Ordenado de la Ley de Relaciones Colectivas de Trabajo, establece los niveles de negociación colectiva. En ese sentido, artículo $44^{\circ}$ menciona lo siguiente:

- A nivel de empresa: Aplica a los trabajadores de una empresa o a los de una categoría, sección o parte determinada de ella.

- A nivel de rama de actividad: Aplica a trabajadores de una misma actividad económica o parte determinada de ella. 
- A nivel de gremio: Aplica a los trabajadores de una misma profesión, oficio o especialidad en distintas empresas.

En esa misma línea, el artículo $45^{\circ}$ del Texto Único Ordenado de la Ley de Relaciones Colectivas de Trabajo, menciona que: "Si no existe previamente una convención colectiva en cualquier nivel de los señalados en el artículo anterior, las partes decidirán, de común acuerdo, el nivel en que entablarán la primera convención. A falta de acuerdo, la negociación se llevará a nivel de empresa".

En estos cuerpos legales se mencionan primeramente los niveles de negociación colectiva que pueden tener las partes y, asimismo, se establece que si las partes no llegan a un acuerdo sobre el nivel en el cual quieren negociar, la negociación obligatoriamente se llevará a nivel de empresa.

b) Cuando durante la negociación se advierten actos de mala fe contra dilatar, entorpecer o evitar llegar a un acuerdo.

En este supuesto, el Árbitro o Tribunal Arbitral son quienes evalúan la procedencia de un arbitraje potestativo por actos de mala fe y ellos tomarán en consideración los criterios de razonabilidad y proporcionalidad de los actos que lo producen.

En esa misma línea el artículo $54^{\circ}$ del Texto Único Ordenado de la Ley de Relaciones Colectivas de Trabajo, de manera complementaria, menciona que: "Las partes están obligadas a negociar de buena fe y a abstenerse de toda acción que pueda resultar lesiva a la contraria, sin menoscabo del derecho de huelga legítimamente ejercitado." 


\subsubsection{RESOLUCIÓN MINISTERIAL $\mathbf{N}^{\circ}$ 284-2011-TR}

Con fecha 24 de setiembre del 2011, se promulga la Resolución Ministerial ํㅜ 2842011-TR donde menciona que las partes están obligadas a negociar de buena fe y a abstenerse de toda acción que pueda resultar lesiva a la parte contraria, sin menoscabo del derecho de huelga legítimamente ejercitado. Asimismo, constituyen actos de mala fe en la negociación colectiva los siguientes:

a) "Negarse a recibir el pliego que contiene el proyecto de convenio colectivo de la contraparte, salvo causa legal o convencional objetivamente demostrable. Asimismo, la negativa a recibirlo a través de la Autoridad Administrativa de Trabajo;

b) Negarse a proporcionar la información necesaria sobre la situación económica, financiera, social y demás pertinentes de la empresa, en la medida en que la entrega de tal información no sea perjudicial para ésta;

c) Negarse a entregar la información acordada por las partes o precisada por la Autoridad Administrativa de Trabajo;

d) No guardar reserva absoluta sobre la información recibida siempre que la misma no sea de carácter público;

e) Negarse a recibir a los representantes de los trabajadores o a negociar en los plazos y oportunidades establecidas en la Ley de Relaciones Colectivas de Trabajo y su Reglamento;

f) Ejercer presión para obtener el reemplazo de los integrantes de la representación de los trabajadores o del empleador; 
g) Ejercer fuerza física en las cosas, o física o moral en las personas, durante el procedimiento de negociación colectiva;

h) Los actos de hostilidad ejercidos contra los representantes de los trabajadores o los trabajadores afiliados al sindicato;

i) El incumplimiento injustificado de las condiciones acordadas por las partes para facilitar la negociación;

j) Cualquier práctica arbitraria o abusiva con el objeto de dificultar, dilatar, entorpecer o hacer imposible la negociación colectiva;

k) Ejecutar actos de injerencia sindical, tales como, intervenir activamente en la organización de un sindicato; ejercer presiones conducentes a que los trabajadores ingresen a un sindicato determinado; discriminar entre los diversos sindicatos existentes otorgando a unos y no a otros, injusta y arbitrariamente, facilidades o concesiones extracontractuales; o condicionar la contratación de un trabajador a la firma de una solicitud de afiliación a un sindicato o de una autorización de descuento de cuotas sindicales por planillas de remuneraciones; $y$

l) Discriminar entre trabajadores con el fin exclusivo de incentivar o desestimular la afiliación o desafiliación sindical."

Sin embargo, en la misma de Resolución menciona que: "Los actos de mala fe enunciados en los literales anteriores no constituyen una lista taxativa." 
El Comité de Libertad Sindical de la OIT ha desarrollado enormemente que tanto el empleador u empleadores y los trabajadores u organización de trabajadores actúen de buena fe y ayuden a llegar a un acuerdo.

En ese mismo sentido, el Tribunal Constitucional en el numeral 16 de la sentencia recaída en el Expediente $\mathrm{N}^{\circ}$ 03561-2009-PA-TC, ha precisado que: "Para que la negociación colectiva funcione eficazmente, las dos partes deben actuar con buena fe y lealtad para el mantenimiento de un desarrollo armonioso del proceso de negociación colectiva, es decir, deben realizar un esfuerzo sincero de aproximación mutua para obtener un convenio".

\subsubsection{DECRETO SUPREMO $\mathrm{N}^{\circ}$ 009-2017-TR}

Con fecha 30 de mayo del 2017, se promulga el Decreto Supremo № 009-2017-TR donde se modifica el Reglamento de la Ley de Relaciones Colectivas de Trabajo aprobado por Decreto Supremo Nº11-92-TR.

El citado decreto supremo modifica los artículos $46^{\circ}, 60^{\circ}$ y $61^{\circ}$-A del Reglamento de la Ley de Relaciones Colectivas de Trabajo, los cuales, fueron redactados de la siguiente manera:

“Artículo 46.- El arbitraje previsto en el Artículo 61 de la Ley procede siempre que ocurra alguna de las causales previstas en el presente Reglamento, salvo que los trabajadores opten por ejercer alternativamente el derecho de huelga, de conformidad con el Artículo 62 de la Ley. 
La Oficina de Economía del Trabajo y Productividad, o la que haga sus veces, del Ministerio de Trabajo y Promoción del Empleo por propia iniciativa podrá solicitar en el curso del procedimiento de negociación directa o de conciliación, la información necesaria que le permita dar cumplimiento a lo ordenado por el artículo 56 de la Ley."

Asimismo, en relación al artículo 60 , el Decreto Supremo $N^{\circ}$ 009-2017-TR, modificó su redacción de la siguiente manera:

Artículo 60.- Los expedientes de negociación colectiva y del procedimiento arbitral constituyen una unidad que se conservará en los archivos de la Autoridad Administrativa de Trabajo competente.

“El presidente del Tribunal Arbitral o el árbitro único debe remitir a la Autoridad Administrativa de Trabajo competente el expediente arbitral en su totalidad dentro de los cinco (5) días hábiles de emitido el laudo arbitral o resuelto cualquier recurso que puedan interponer las partes, bajo sanción de separación del Registro Nacional de Árbitros de Negociaciones Colectivas.

Las Autoridades Regionales de Trabajo envían a la Dirección General de Trabajo, dentro de los tres (3) días hábiles de recibidos, copia fedateada de los laudos arbitrales o por medios electrónicos, bajo responsabilidad.

La Dirección General de Trabajo centraliza los laudos arbitrales y, trimestralmente, los publica en el portal web del Ministerio de Trabajo y Promoción del Empleo. 
El Registro Nacional de Árbitros de Negociaciones Colectivas cuenta con información sobre la hoja de vida de los árbitros, los arbitrajes en los que hayan participado y los laudos que hayan emitido.

Los árbitros inscritos en dicho Registro deben actualizar dicha información en forma permanente, y como mínimo dentro del primer mes de cada año."

Finalmente, en relación al artículo 61- $\mathrm{A}^{\circ}$, el Decreto Supremo antes citado modificó su redacción conforme al siguiente detalle:

“Artículo 61-A.- Arbitraje Potestativo

Habiéndose convocado al menos seis (6) reuniones de trato directo o de conciliación, y transcurridos tres (3) meses desde el inicio de la negociación, cualquiera de las partes tiene la facultad de interponer el arbitraje potestativo, ocurridos los siguientes supuestos:

a) Las partes no se ponen de acuerdo en la primera negociación, en el nivel o su contenido; $o$,

b) Cuando durante la negociación se adviertan actos de mala fe que tengan por efecto dilatar, entorpecer o evitar el logro de un acuerdo."

Lo resaltado en negrita son las modificaciones que se introdujeron en los artículos antes señalados, una modificación resaltante es la que se menciona en el artículo $61^{\circ}$-A donde para poder interponer un arbitraje potestativo se debería haber convocado al menos seis (06) reuniones de trato directo o de conciliación, y transcurrido tres (03) meses desde el inicio de la negociación. 
A continuación, el mismo Decreto Supremo, incorporó los artículos $61^{\circ}$-B y $61^{\circ}$-C al Reglamento de la Ley de Relaciones Colectivas de Trabajo, de la siguiente manera:

\section{“Artículo 61-B.- Designación de los árbitros y presidente del Tribunal Arbitral}

Activado el arbitraje, las partes deben elegir a sus árbitros en un plazo no mayor de cinco (5) días hábiles perentorios. De no hacerlo una de ellas, la Autoridad Administrativa de Trabajo elige al árbitro correspondiente, cuyo honorario asume la parte responsable de su elección.

Elegidos los árbitros, ellos acuerdan la elección del Presidente del Tribunal Arbitral en un plazo no mayor de cinco (5) días hábiles perentorios. De no llegar a un acuerdo dentro del plazo anterior, la Autoridad Administrativa de Trabajo procede a la elección del Presidente Del Tribunal Arbitral, quien se desempeñará como tal salvo que las partes, de común acuerdo, propongan un nombre distinto dentro del plazo de tres (3) días hábiles de comunicada la elección a ambas partes.

Las designaciones efectuadas por la Autoridad de Administrativa de Trabajo se realizan mediante sorteos públicos y aleatorios, sobre la nómina de árbitros inscritos

en el Registro Nacional de Árbitros de Negociaciones Colectivas, en un plazo no mayor de diez (10) días hábiles desde que se toma conocimiento del vencimiento del plazo para designar al árbitro o Presidente del Tribunal Arbitral.

Salvo pacto en contrario, no puede ser designado como árbitro o Presidente del Tribunal Arbitral quien dentro de los dos (2) últimos años se haya desempeñado como parte, árbitro, abogado o asesor en algún arbitraje laboral colectivo, potestativo o voluntario, seguido por alguna de las partes. Los dos (2) años se 
contabilizan desde la emisión del laudo arbitral. Se exceptúan de esta disposición los árbitros que sean escogidos en arbitrajes unipersonales.

Si por alguna circunstancia alguno de los árbitros dejara de asistir a más de una sesión o renunciara, la parte afectada debe sustituirlo en el término no mayor de tres (3) días hábiles. En caso de no hacerlo, el presidente del Tribunal Arbitral solicita a la Autoridad Administrativa de Trabajo su sustitución.

Constituido el Tribunal Arbitral, dentro de los cinco (5) días hábiles siguientes, las partes entregan al tribunal su propuesta final, de ser el caso, en forma de proyecto de convenio colectivo, con copia para la otra parte, que le será entregado a éste por el presidente del Tribunal Arbitral. Dentro de los cinco (5) días hábiles siguientes, las partes podrán formular al tribunal las observaciones debidamente sustentadas, que tuvieran respecto."

Asimismo, en relación al artículo 61-Cㅜ el Decreto Supremo № 009-2017-TR precisó:

\section{“Artículo 61-C.- Reglas especiales para el arbitraje potestativo}

Son aplicables al arbitraje potestativo las reglas del procedimiento arbitral establecidas en los artículos 55, 56, 58, 59, 60 y 61 del Reglamento.

En ningún caso, el arbitraje potestativo puede ser utilizado en desmedro del derecho de huelga."

El contenido de estos nuevos artículos se encontraba estipulado en el antiguo artículo 61ํ-A aprobado por el Decreto Supremo Nº 014-2011-TR. 


\subsubsection{PROCEDIMIENTO DEL ARBITRAJE POTESTATIVO}

Para el arbitraje potestativo, se aplica lo señalado en los artículos $47^{\circ}$ al $61^{\circ}$ del Reglamento del Texto Único Ordenado de la Ley de Relaciones Colectivas de Trabajo.

No obstante, con la modificatoria realizada por el Decreto Supremo No 009-2017-TR, que introduce el artículo $61^{\circ}-\mathrm{B}$ al Reglamento antes mencionado, se ha modificado el procedimiento de designación de los árbitros y presidente del Tribunal Arbitral que antes se tenía.

2.1.6.1 Designación de los árbitros por las partes:

En tal sentido, las partes podrán designar a sus árbitros en un plazo no mayor de cinco (05) días hábiles, en caso que no lo realizaran, la Autoridad Administrativa de Trabajo lo hace. Escogidos los árbitros, ellos eligen al Presidente del Tribunal Arbitral en un plazo no mayor a cinco (05) días hábiles, en caso que no lleguen a un acuerdo, la Autoridad Administrativa de Trabajo lo realiza.

2.1.6.2 Designación de los árbitros por la Autoridad Administrativa de Trabajo

Las elecciones que hace la Autoridad Administrativa de Trabajo lo realiza en sorteos públicos y aleatorios y en base a los árbitros que se encuentren inscritos en el Registro Nacional de Árbitros de Negociaciones Colectivas en un plazo no mayor de diez (10) días hábiles, contados desde el día que se tiene conocimiento del vencimiento para designar al árbitro o Tribunal Arbitral.

\subsubsection{Requisitos para ser árbitro}


Salvo que las partes lo acuerden, los árbitros designados no deberán haber desempeñado, en relación con las partes del arbitraje, funciones de parte, árbitro, abogado o asesor en algún arbitraje laboral colectivo dentro de los dos (02) últimos años, este plazo se cuenta desde el día de emisión del Laudo Arbitral. No aplica esta restricción para los arbitrajes unipersonales.

\subsubsection{Sustitución de los árbitros}

En caso que alguno de los árbitros dejara de asistir a más de una sesión o renuncie, la parte afectada podrá sustituirlo en un plazo no mayor de tres (03) días hábiles; en caso de no hacerlo, la Autoridad Administrativa de Trabajo lo realizará.

\subsubsection{Presentación de propuestas por las partes}

Constituido el Tribunal Arbitral, las partes deberán presentar sus propuestas finales con copia para la otra parte, dentro de los cinco (05) días hábiles siguientes. Ya transcurridos, las partes podrán efectuar sus observaciones debidamente sustentadas.

\subsubsection{Etapa de actuaciones}

El árbitro o Tribunal Arbitral podrán solicitar todo clase de pruebas, investigaciones, pericias, informes, documentos públicos y privados de propiedad o en posesión de las partes o de terceros dentro de los treinta (30) días naturales, contados desde la fecha de iniciado el proceso arbitral.

Dentro el plazo de cinco (05) días hábiles de concluida la etapa mencionada en el párrafo anterior, el árbitro o Tribunal Arbitral convocará a las partes a fin de darle a conocer el Laudo Arbitral. 
Cabe señalar, que en nuestra legislación han existido varias modificaciones respecto al arbitraje potestativo en la negociación colectiva: desde que en sus inicios se permitió el arbitraje en caso que no se llegue a un acuerdo en la negociación directa y conciliación; de ahí, un Decreto Supremo del año 2011 introduce una nueva figura, a raíz de dos sentencias del Tribunal Constitucional, que sería el arbitraje potestativo con sus dos causales de procedencia hasta llegar actualmente con un Decreto Supremo del año 2017, donde se añade básicamente la condición de procedencia de un arbitraje potestativo y señala que se debe convocar al menos seis (06) reuniones de trato directo o de conciliación, y transcurridos tres (03) meses desde el inicio de la negociación.

Finalmente, el Decreto Supremo del año 2017 incorpora nuevos requisitos para designar a los árbitros en los arbitrajes potestativos y esto hace que exista imparcialidad en su elección y resolución y que se reduzca el número de árbitros hábiles para poder ejercer con esas funciones.

\subsection{CRÍTICAS AL ARBITRAJE POTESTATIVO}

\subsubsection{Vulneración al Principio de Jerarquía Normativa}

La Constitución de 1993, en dos capítulos de su Título II, analiza y determina los principios informantes y la estructura general del Estado Peruano. El primer capítulo define los fines y deberes del Estado, precisando de manera clara el marco jurídico constitucional aplicable haciendo especial hincapié en la identidad, soberanía, legalidad y legitimidad. 
En ese mismo sentido, con relación al marco jurídico aplicable, la Carta Magna, a través de su artículo 51 ${ }^{\circ 8}$, señala la importancia superior de la Constitución y su consonancia para con la jerarquía normativa estableciendo de manera clara principios reguladores de la actividad normativa del Estado.

La sucesión jerárquica señalada por el artículo $51^{\circ}$ refiere que, luego de la Constitución, aparecen las leyes emitidas por el Congreso, los decretos legislativos emitidos por el Poder Ejecutivo, que proceden de la expresa delegación de facultades autorizadas por el Congreso y posteriormente los decretos y resoluciones que de ninguna manera pueden transgredir ni desnaturalizar la ley.

Al respecto, Tomas Requena López ${ }^{9}$, señala que el principio de jerarquía normativa “es la imposición de un modo de organizar las normas vigentes en un Estado, consistente en hacer depender la validez de unas sobre otras. Así, una norma es jerárquicamente superior a otra, cuando la validez de esta depende de aquella".

Sobre el particular el Tribunal Constitucional ha señalado:

“El orden jurídico es un sistema orgánico, coherente e integrado jerárquicamente por normas de distinto nivel que se encuentran interconectadas por su origen; es decir, que unas normas se fundan en otras o son consecuencia de ellas ". ${ }^{10}$

Agregando que:

\footnotetext{
${ }^{8}$ Artículo 51.- La Constitución prevalece sobre toda norma legal; la ley, sobre las normas de inferior jerarquía, y así sucesivamente. La publicidad es esencial para la vigencia de toda norma del Estado.

${ }^{9}$ REQUENA LÓPEZ, Tomás. El principio de jerarquía normativa, Ob. Cit., p. 339.

${ }^{10}$ Caso Sesenta y cuatro Congresistas de la República contra la Ley No 26285, Exp. No 005-2003-AI/TC, fundamento 3.
} 
"Con ello se postula una prelación normativa con arreglo a la cual, las normas se diversifican en una pluralidad de categorías que se escalonan en consideración a su rango jerárquico. Dicha estructuración se debe a un escalonamiento sucesivo tanto en la producción como en la aplicación de las normas jurídicas. Esta jerarquía se fundamenta en el principio de subordinación escalonada. Así la norma inferior encuentra en la superior la razón de su validez; y, además obtiene ese rasgo siempre que hubiese sido conocida por el órgano competente y mediante el procedimiento previamente establecido en la norma superior." 11

Ahora bien, conforme se ha señalado en extenso en el presente trabajo, el arbitraje potestativo fue establecido mediante el Decreto Supremo $\mathrm{N}^{\circ}$ 014-2011, el mismo que modificó, a través de Decreto Supremo N 010-2003, el Reglamento de la Ley de Relaciones Colectivas de Trabajo, norma que se encontraba entonces regulada en el Decreto Ley N 25593.

Si bien consideramos conforme a ley, que la modificación de un Reglamento aprobado por Decreto Supremo sea modificada por otro Decreto Supremo, debe resaltarse el hecho que dicha norma no puede variar ni modificar la Ley que está sujeta a su regulación; hacerlo, contravendría el principio de jerarquía normativa y resultaría inconstitucional.

El arbitraje potestativo, al conformarse de la dación de un Decreto Supremo, contraviene el principio constitucional antes señalado, pues varía el contenido de una norma de mayor jerarquía (Decreto Ley $\mathrm{N}^{\circ}$ 25593), atentando de esta manera contra la seguridad jurídica de las empresas y trabajadores, toda vez que los laudos que se emitan en el marco de esta clase de arbitraje podría ser luego discutidos y dejados sin efecto.

\footnotetext{
${ }^{11}$ Ibíd., fundamento 5
} 
En tal sentido, consideramos que lo correcto hubiera sido que la dación de este tipo de procedimientos se hubiese previsto en un Decreto Ley y no a través de un Decreto Supremo.

\subsubsection{La ilegal obligatoriedad del arbitraje potestativo}

Conforme se ha señalado previamente, el arbitraje, como mecanismo de solución de conflictos, requiere en esencia el consentimiento de las partes contrayentes a efectos estas, de manera libre y voluntaria, y que acaten la decisión de un tercero en la resolución de un conflicto que de manera directa no pudo ser resuelto.

El arbitraje de acuerdo a su naturaleza, tiene un origen fundamentalmente contractual, pues a través de este mecanismo, las partes optan voluntariamente a someter sus conflictos al fallo de un tercero imparcial; sin embargo, es importante resaltar que a pesar de que el arbitraje se constituye como un mecanismo heterocompositivo de resolución de conflictos, resulta siempre necesario la existencia de un mínimo de presencia autocompositiva, que no es otra cosa que la voluntad de las partes a someterse al arbitraje y respetar lo que en él se laude.

Roque Caivano", citando a Aramburú Menchaca, ha precisado que "entre las razones que llevan a las personas a buscar en el arbitraje la solución a sus conflictos, indudablemente la expresión de confianza es la más importante, por cuanto significa un reconocimiento de la pericia, de la capacidad intelectual del árbitro, del sentido de equidad que pondrá en la resolución del pleito; pero ante todo un reconocimiento a su probidad”.

${ }^{12}$ CAIVANO, Roque. Arbitraje. 2da. Ed. AdHoc, Buenos Aires, 2008 p. 50 
En ese mismo sentido, el Tribunal Constitucional en el fundamento 10 de la sentencia recaída en el Expediente Nº0061-2008-PA/TC - Caso Rímac Internacional -, precisó:

"al normar un arbitraje obligatorio se contraviene el principio de autonomía de la voluntad y el derecho a la tutela judicial efectiva, en su vertiente de acceso a la justicia y al juez natural.”

Cabe precisar entonces, que el arbitraje en tanto voluntario, resulta constitucional debido a que su origen tiene como fundamento el principio de autonomía de la voluntad que constituye la esencia y fundamento del proceso arbitral.

Sobre el particular, la Organización Internacional del Trabajo (OIT), en su Recomendación 092, ha señalado entre otros aspectos, que resulta fundamental que los conflictos colectivos laborales se resuelvan atendiendo a mecanismos voluntarios que permitan ambas partes (en el conflicto de trabajo) participen de forma libre y espontánea en el arribo de un acuerdo. En ese sentido, su artículo $6^{\circ}$ precisa que si un conflicto laboral, previo consenso de las partes, fue sometido a arbitraje "debería estimularse a las partes para que se abstengan de recurrir a huelgas y a lock outs mientras dure el procedimiento de arbitraje y para que acepten el laudo arbitral".

Sin perjuicio de lo señalado, y pese al origen voluntario del arbitraje, en el Perú el legislador ha determinado la necesidad de instaurar mecanismos obligatorios de arbitraje en materia laborar; en ese sentido, el artículo $68^{\circ}$ del Texto Único Ordenado de la Ley de Relaciones Colectivas de Trabajo ha previsto la posibilidad de que la autoridad administrativa "promueva un arreglo directo u otra forma de solución pacífica del conflicto" en los casos que una "huelga se prolongue excesivamente en el tiempo, 
comprometiendo gravemente a una empresa o sector productivo, o derive en actos de violencia, o de cualquier manera, asuma características graves por su magnitud o consecuencias".

Conforme a lo señalado hasta el momento, queda claro entonces que el arbitraje laboral en el Perú es voluntario fundamentalmente, y excepcionalmente puede instaurarse de manera obligatoria en casos de afectación de servicios públicos esenciales. En tal sentido, consideramos que el arbitraje potestativo no se encuadra en ninguno de los supuestos anteriormente señalados, puesto por su naturaleza no reviste carácter voluntario de los contrayentes, ya que la obligatoriedad de su sometimiento depende de una sola voluntad, y tampoco se enmarca en las causales del arbitraje obligatorio.

En esta misma línea, Fernando Elías Mantero ${ }^{13}$ señala que el arbitraje potestativo "no es otra cosa que un arbitraje forzoso u obligatorio encubierto", posición que compartimos y que consideramos va contra lo regulado por la propia Ley de Relaciones Colectivas de Trabajo, en tanto instaura una nueva figura de arbitraje obligatorio, e incluso de las recomendaciones de la OIT.

Consideramos entonces, que nuevamente lo correcto hubiera sido que la creación de este tipo de arbitraje, posiblemente necesario en algunos conflictos labores, hubiese sido encausado a través de la/regulación establecida dentro del marco de los arbitrajes obligatorios.

\subsubsection{La designación de los árbitros}

\footnotetext{
${ }^{13}$ Elías Mantero Fernando, Acerca de la implementación del arbitraje potestativo y la creación del registro nacional de árbitros en materia de negociación colectiva. En Actualidad Laboral. Noviembre 2012
} 
Conforme se ha señalado previamente, un problema central en la estructura regulada para el arbitraje potestativo radica su creación, esto es que la norma que la origina no fue sustentada en una Ley, sino por lo contrario en un Decreto Supremo que únicamente debió reglamentar la Ley mas no modificarla ni innovarla.

En este extremo, surge un problema en cuanto a los requisitos para la designación de los árbitros dentro de un proceso arbitral potestativo.

La Ley de Relaciones Colectivas de Trabajo, a través de su artículo $50^{\circ}$ no ha requerido para la designación de los árbitros, dentro de los procesos arbitrales voluntarios u obligatorios, que estos cuenten con un grado académico determinado. Sin embargo, conforme puede advertirse del Decreto Supremo $N^{\circ}$ 014-2011-TR, norma que modifica el Reglamento de la Ley de Relaciones Colectivas, para la designación de los árbitros dentro de un arbitraje potestativo se requiere que estos se encuentren inscritos en el Registro Nacional de Árbitros de Negociación Colectiva, siendo imprescindible a su vez, que es estos sean "profesionales de reconocida trayectoria".

Conforme a lo señalado, queda claro una vez más que la norma destinada a reglamentar la Ley de Relaciones Colectivas de Trabajo, modifica el contenido de la ley imponiendo limitaciones no reguladas por esta, contraviniendo nuevamente el principio de jerarquía normativa, en tanto se estaría variando el contenido de una norma de mayor jerarquía (Decreto Ley $\mathrm{N}^{\circ}$ 25593) atentando de esta manera contra la seguridad jurídica de las empresas y trabajadores, toda vez que los laudos que se emitan en el marco de esta clase de arbitraje podría ser luego discutidos y dejados sin efecto, en vías de recusación arbitral. 
En tal sentido, consideramos que, si bien resulta adecuado que los árbitros que conozcan procesos arbitrales en materia laboral tengan cualificaciones necesarias para resolver, en criterios de equidad y justicia, un conflicto laboral, es preponderante que la norma que así lo regule, o modifique, sea mínimamente de igual jerarquía que la que lo regula.

\subsubsection{La mala fe como causal de arbitraje potestativo}

Conforme ha sido señalado previamente, el arbitraje potestativo, por su naturaleza, busca resolver a través de un tercero el conflicto laboral generado entre un sindicato y sus empleadores. Sin embargo, resulta predominante apreciar que para que este mecanismo se configure es necesario que se presenten dos supuestos:

a) Que las partes no se pongan de acuerdo en la primera negociación, en su nivel o contenido y, el segundo lugar,

b) Cuando se advierten actos de mala fe que tengan por efecto dilatar, entorpecer o evitar el acuerdo.

Si bien es cierto, la norma expresa solo está dos causales para su procedencia, resulta por lo menos "interesante" la figura de la "mala fe" en la configuración de este tipo de arbitraje laboral. En el pasado, si los empleadores incurrían en actos de "mala fe", en el peor de los casos podrían hacerse acreedores de una multa administrativa; sin embargo, en la actualidad es probable que les sea impuesto un arbitraje por la otra parte, en este caso, el sindicato. 
Ante esta situación, resulta relevante entonces señalar qué precisa la norma respecto a la mala fe de las partes, y en un segundo momento, analizar los criterios utilizados para su determinación.

\subsubsection{Causales de la mala fe y observaciones a la instancia que evalúa su configuración}

En primer término, debemos señalar que el Decreto Supremo No 014-2011-TR, no hace referencia a los criterios que deben utilizarse para definir estos actos, limitándose a través de su artículo primero a señalar que esta figura se aplicará únicamente cuando estos actos tengan por objeto dilatar, entorpecer o evitar el acuerdo.

Contrario al correcto proceder de la administración, en lugar de incluir las causales habilitantes de la "mala fe" dentro del contexto de una Ley, o en el peor de los casos dentro de un Decreto Supremo que la reglamente, el Ministerio de Trabajo y Promoción del Empleo, a través del artículo $1^{\circ}$ de la Resolución Ministerial N²84-2011-TR, ha señalado las causales a través de las cuales se configura esta acción lesiva ${ }^{14}$, precisando además que

14 “ “... Constituyen actos de mala fe en la negociación colectiva, los siguientes: a) Negarse a recibir el pliego que contiene el proyecto de convenio colectivo de la contraparte, salvo causa legal o convencional objetivamente demostrable. Asimismo, la negativa a recibirlo a través de la Autoridad Administrativa de Trabajo; b) Negarse a proporcionar la información necesaria sobre la situación económica, financiera, social y demás pertinentes de la empresa, en la medida en que la entrega de tal información no sea perjudicial para ésta; c) Negarse a entregar la información acordada por las partes o precisada por la Autoridad Administrativa de Trabajo; d) No guardar reserva absoluta sobre la información recibida siempre que la misma no sea de carácter público; e) Negarse a recibir a los representantes de los trabajadores o a negociar en los plazos y oportunidades establecidas en la Ley de Relaciones Colectivas de Trabajo y su Reglamento; f) Ejercer presión para obtener el reemplazo de los integrantes de la representación de los trabajadores o del empleador; g) Ejercer fuerza física en las cosas, o física o moral en las personas, durante el procedimiento de negociación colectiva; h) Los actos de hostilidad ejercidos contra los representantes de los trabajadores o los trabajadores afiliados al sindicato; i) El incumplimiento injustificado de las condiciones acordadas por las partes para facilitar la negociación; j) Cualquier práctica arbitraria o abusiva con el objeto de dificultar, dilatar, entorpecer o hacer imposible la negociación colectiva; k) Ejecutar actos de injerencia sindical, tales como, intervenir activamente en la organización de un sindicato; ejercer presiones conducentes a que los trabajadores ingresen a un sindicato determinado; discriminar entre los diversos sindicatos existentes otorgando a unos y no a otros, injusta y arbitrariamente, facilidades o concesiones extracontractuales; o condicionar la contratación de un trabajador a la firma de una solicitud de afiliación a un sindicato o de una autorización de descuento de cuotas 
"los actos de mala fe enunciados en los literales anteriores no constituyen una lista taxativa", siendo el caso que la valoración de los supuestos de procedencia del arbitraje potestativo deberá ser analizada por el Tribunal Arbitral dentro del proceso arbitral.

Sobre el particular, nos llama la atención dos puntos relevantes. En primer lugar, consideramos que la enumeración de tales causales debió hacerse en una norma habilitante de mayor rango; y en segundo lugar, que al precisar la Resolución Ministerial $N^{\circ}$ 2842011-TR que las causales enunciadas para la mala fe no constituyen una lista taxativa, se deja nuevamente dentro de un marco netamente subjetivo los alcances de esta.

De este modo, Jorge Toyama Miyagusuku ${ }^{15}$ ha precisado que la función de determinar qué conductas configuran actos de mala fe, debe ser determinada por el Ministerio de Trabajo, instancia imparcial que debería, previo al inicio del arbitraje, determinar con exactitud si existe o no mala fe en la conducta de las partes, en tanto esta instancia cuenta con suficiente información de la empresa y es además quien procesa el dictamen económico de esta entre otros.

Conforme a lo señalado por Toyama Miyagusuku, tenemos la opinión de que, al margen de que instancia sea la que valore que acciones configuran la "mala fe" de las partes, no puede encargarse tal evaluación al Tribunal Arbitral, pues existe riesgo que los árbitros admitan a discreción cualquier causal injustificada para iniciar el procedimiento. En tal sentido, consideramos que, a través un proceso sumamente breve, el Ministerio de Trabajo o la instancia que haga de sus veces, valore si realmente nos encontramos ante un

sindicales por planillas de remuneraciones; y, i) Discriminar entre trabajadores con el fin exclusivo de incentivar o desestimular la afiliación o desafiliación sindical.

${ }^{15}$ En entrevista brindada al Diario Gestión el 24 de agosto de 2012. 
supuesto que pretenda dilatar, entorpecer o evitar un acuerdo y de no configurarse el caso ordene la continuación de la negociación, teniendo siempre las partes la facultad de suscribir un compromiso arbitral que las sujeciones a un arbitraje voluntario posterior.

\subsubsection{En relación a los criterios utilizados para determinar la mala fe}

Conforme a lo señalado precedentemente, la actual redacción de la Resolución Ministerial $\mathrm{N}^{\circ}$ 284-2011-TR prescribe que la valoración de los supuestos de procedencia del arbitraje potestativo deberá ser analizada por el Tribunal Arbitral dentro del proceso.

En ese contexto, y habiendo planteado previamente que dejar abierta la facultad de determinar la configuración de la mala fe a los árbitros resulta contraproducente, corresponde analizar algunas sentencias de tribunales arbitrales que sobre una misma materia laudan en sentidos abiertamente contrarios.

a) Arbitraje potestativo entre Sindicato de Trabajadores de Cerámica San Lorenzo y la Empresa San Lorenzo.

En este proceso arbitral, el tribunal declaró improcedente el arbitraje potestativo solicitado por el Sindicato de Trabajadores bajo el siguiente fundamento:

"No basta la imputación de conductas del empleador que puedan ser modificadas como actos de mala fe genérica, sino que, de manera indispensable, estas conductas deben estar relacionadas afecta el ejercicio libre de la negación colectiva debiendo existir necesariamente una relación entre el acto calificado de mala fe y el desarrollo de la negociación”. 
En esta decisión se puede apreciar que para el colegiado arbitral no es suficiente la configuración de hechos que puedan ser catalogados como contrarios a la buena fe, sino que resulta indispensable que dichos actos lesivos se encuentren vinculados a la negociación.

b) Arbitraje potestativo entre el Sindicato de Trabajadores Textiles y Químicos de Arias Industrial S.A. y Arias Industrial S.A.

En este caso, de manera similar al arbitraje comentado precedentemente, el tribunal declaró improcedente el arbitraje potestativo considerando que:

"no basta la imputación de conductas cometidas por el empleador que puedan ser calificadas como actos de mala fe genérica, sino que constituye un requisito sine qua non que estas conductas afecten negativamente el ejercicio libre de la negociación colectiva, debiendo existir necesariamente una relación directa entre el acto calificado de mala fe y el desarrollo de la negociación"

En este caso, apreciamos nuevamente el criterio restrictivo respecto de la configuración de la mala fe dentro del arbitraje potestativo, reiteradamente se señala que para que este se materialice, es indispensable que el acto lesivo se encuentre vinculado al desarrollo de la negociación.

c) Arbitraje potestativo entre el Centro Federado de Empleados del BBVA Banco Continental y el Banco Continental. 
En este proceso, a diferencia de los anteriormente comentados, el tribunal arbitral consideró como mala fe los siguientes argumentos señalados por el Centro Federado:

"1. El BBVA no habría cumplido con su deber de entrega de información económico-financiera a la ATT, ya que la misma fue, a decir del Tribunal, incompleta e inoportuna.

2. Que el BBVA habría incurrido en la práctica antisindical contra el Secretario General del Sindicato al supuestamente no evaluársele como a los demás trabajadores ni informársele de la evaluación."

Conforme puede apreciarse, se puede inferir válidamente que únicamente la primera causal guarda relación con el desarrollo de la negociación, siendo el caso que el segundo argumento utilizado por el tribunal no solo no se vincula con la negociación, sino que por en cambio versa sobre una materia ajena al conflicto laboral.

De lo señalado, queda claro que cada tribunal en razón de su independencia y sobre todo de su criterio, puede laudar de manera independiente respecto de demás laudos arbitrales, eso no se encuentra en discusión; lo que se cuestiona es el hecho de que ante una causal habilitante (del arbitraje potestativo), como es la mala fe, no exista un criterio determinado para su evaluación y que el criterio subjetivo que la circunscribe varíe de laudo en laudo, no resultando las herramientas normativas emitidas por el Poder Ejecutivo clarificadoras.

\subsubsection{El arbitraje potestativo en empresas estatales}


Un primer punto a evaluar es el hecho de que, en una contienda arbitral de este tipo, lo que normalmente se busca determinar es si es factible o no el otorgamiento de un derecho patrimonial hacia los trabajadores. Este otorgamiento de derechos, frecuentemente se plasma en mejoras salariales, lo que a su vez implica que las empresas puedan o no disponer de recursos para hacer efectivo, de ser el caso, un laudo arbitral.

Conforme se ha señalado reiteradamente, la norma que incorpora al arbitraje potestativo dentro de marco regulatorio laboral, fue el Decreto Supremo $N^{\circ}$ 014-2011-TR, dicho decreto supremo no reglamentó de manera expresa si este mecanismo de solución de conflictos se aplicaría a las empresas estatales o a las empresas privadas; en tal sentido, al no precisar dichos alcances se colige que le son aplicables a ambos regímenes.

Ya se ha mencionado en los considerandos anteriores los problemas que conlleva la inadecuada regulación de este mecanismo de solución de controversias; sin embargo, resulta relevante señalar que dentro del régimen de las empresas públicas, la disponibilidad presupuestaria se encuentra regulada en los artículos $77^{\circ 16}$ y $78^{\circ 17}$ de la Constitución, siendo el caso que esta consideración aparentemente no habría sido observada por el "legislador" en tanto no habría previsto que ante un eventual fallo condenatorio a una empresa estatal, el Estado, a través de su empresa, pudiera verse imposibilitado de dar

\footnotetext{
16 Artículo $77^{\circ}$.- La administración económica y financiera del Estado se rige por el presupuesto que anualmente aprueba el Congreso. La estructura del presupuesto del sector público contiene dos secciones: gobierno central e instancias descentralizadas. El presupuesto asigna equitativamente los recursos públicos, su programación y ejecución responden a los criterios de eficiencia de necesidades sociales básicas y de descentralización. Corresponden a las respectivas circunscripciones, conforme a ley, recibir una participación adecuada del total de los ingresos y rentas obtenidos por el Estado en la explotación de los recursos naturales en cada zona en calidad de canon.

${ }^{17}$ Artículo $78^{\circ}$.- El Presidente de la República envía al Congreso el proyecto de Ley de Presupuesto dentro de un plazo que vence el 30 de agosto de cada año. En la misma fecha, envía también los proyectos de ley de endeudamiento y de equilibrio financiero. El proyecto presupuestal debe estar efectivamente equilibrado. Los préstamos procedentes del Banco Central de Reserva o del Banco de la Nación no se contabilizan como ingreso fiscal. No pueden cubrirse con empréstitos los gastos de carácter permanente. No puede aprobarse el presupuesto sin partida destinada al servicio de la deuda pública.
} 
cumplimiento al mismo si es que el requerimiento presupuestario no se ajusta a la realidad económica de la entidad.

Sobre el particular, la Ley del Sistema General de Presupuesto - Ley № 28411 señala a través de su $70.1^{18}$ que para el pago de sumas de dinero por efecto de sentencias judiciales en calidad de cosa juzgada o Laudos Arbitrales, la empresas estatales pueden afectar hasta el cinco por ciento (5\%) de los montos aprobados en el Presupuesto Institucional de Apertura (PIA), con excepción de los fondos públicos correspondientes a las Fuentes de Financiamiento Donaciones y Transferencias y Operaciones Oficiales de Crédito Interno y Externo, la reserva de contingencia y los gastos vinculados al pago de remuneraciones, pensiones y servicio de tesorería y de deuda.

Asimismo, queda claro que los regímenes estatales, a diferencia de los privados, enmarcan sus presupuestos en periodos anuales; en tal sentido, consideramos que los laudos arbitrales en los cuales se vincule (o condene) a empresas estatales, deben ajustarse al presupuesto de dichas entidades, caso contrario podrían desencadenarse una crisis financiera que a mediano plazo perjudique al mismo trabajador.

Desde una perspectiva socio económica, debe precisarse que las empresas del estado se encuentran reguladas dentro del Presupuesto General de la República, el mismo que es planificado y determinado previo al inicio de cada año fiscal. En tal sentido, un incremento salarial no planificado no solo perjudica a la empresa sino a la sociedad misma, pues al

\footnotetext{
${ }^{18}$ Artículo 70.- Pago de sentencias judiciales 70.1 Para el pago de sumas de dinero por efecto de sentencias judiciales en calidad de cosa juzgada, se afecta hasta el cinco por ciento $(5 \%)$ o hasta un mínimo de tres por ciento (3\%), según sea necesario, de los montos aprobados en el Presupuesto Institucional de Apertura (PIA), con excepción de los fondos públicos correspondientes a las fuentes de financiamiento Donaciones y Transferencias y Operaciones Oficiales de Crédito Interno y Externo, la reserva de contingencia y los gastos vinculados al pago de remuneraciones, pensiones y servicio de tesorería y de deuda. Esta norma comprende, entre otros, la atención de sentencias judiciales en calidad de cosa juzgada por adeudos de beneficios sociales."
} 
destinarse presupuesto al pago de una contingencia no prevista, se reduce el mismo (presupuesto) a otros programas planificados por el Estado.

Sobre este punto, Jorge Toyama, en una entrevista publicada en la Agencia Andina de fecha tres de mayo de 2012, señaló:

“(...) en algunos conflictos entre sindicatos y empleadores, los árbitros resuelven que se abone al trabajador sumas por encima de las posibilidades económicas reales de las entidades, sobre todo en el sector público, ocasionándoles dificultades presupuestales.

"Si esto se llegara a generalizar, el arbitraje laboral se convertiría en un mecanismo que lleve a serios problemas económicos a entidades públicas y privadas. Los resultados de los laudos deben respetar el equilibrio presupuestal de las empresas"

Asimismo, en relación al criterio arbitral en este tipo de controversias, acotó:

"Los árbitros tienen autonomía en sus resoluciones, pero creo que estas deberían tener más aproximación o sensibilidad en relación con lo que es el Estado. La tendencia de los arbitrajes potestativos es a no tomar mucho en cuenta los presupuestos públicos”

Conforme a lo señalado por Toyama, consideramos que debe revisarse el marco legal concerniente a los laudos arbitrales, a efectos de alinear las posibilidades financieras de una empresa con la razonable necesidad de los trabajadores que anhelan a obtener incrementos salariales. En ese mismo sentido, consideramos que no podrá ser factible el cumplimiento de un laudo arbitral, cuando una de las partes del conflicto (sindicatos o empresa estatal) 
formulen propuestas inviables y ajenas a la realidad económica de la entidad, no debiendo, en ningún caso, llegar a los extremos de pretensiones salariales descomunales u ofrecimientos de aumentos absurdos.

\subsubsection{La eventual declaratoria de inconstitucionalidad del Decreto Supremo $\mathbf{N}^{\circ}$ 014-2011-}

TR.

Conforme hemos señalado precedentemente, el arbitraje potestativo, al conformarse de la dación de un Decreto Supremo, contraviene el principio constitucional de jerarquía normativa, pues varía a través de un norma reglamentaria, el contenido de una norma de mayor jerarquía (Decreto Ley $\mathrm{N}^{\circ}$ 25593), y atenta, de esta manera, contra la seguridad jurídica de las empresas y trabajadores, toda vez que los laudos que se emitan en el marco de esta clase de arbitraje podrían ser luego discutidos y dejados sin efecto.

En efecto, considerando que el actual marco regulatorio se fundamenta, a criterio nuestro, en una mala técnica legislativa, cabe preguntarse ¿qué sucedería si es que las normas que regula el arbitraje potestativo fueran declaradas inconstitucionales? En un primer término, debemos precisar que el mecanismo a través del cual se declara inconstitucional las normas emitidas por el Estado peruano es la Acción Popular.

En tal sentido, el artículo $81^{\circ}$ de la Código Procesal Constitucional señala que:

"Las sentencias fundadas recaídas en el proceso de inconstitucionalidad dejan sin efecto las normas sobre las cuales se pronuncian. Tienen alcances generales y carecen de efectos retroactivos. Se publican íntegramente en el Diario Oficial El Peruano y producen efectos desde el día siguiente de su publicación. Cuando se declare la inconstitucionalidad de normas tributarias por violación del artículo 74 de 
la Constitución, el Tribunal debe determinar de manera expresa en la sentencia los efectos de su decisión en el tiempo. Asimismo, resuelve lo pertinente respecto de las situaciones jurídicas producidas mientras estuvo en vigencia. Las sentencias fundadas recaídas en el proceso de acción popular podrán determinar la nulidad, con efecto retroactivo, de las normas impugnadas. En tal supuesto, la sentencia determinará sus alcances en el tiempo. Tienen efectos generales y se publican en el Diario Oficial El Peruano.”

Ahora bien, en el caso hipotético que se declarase la nulidad del Decreto Supremo $\mathrm{N}^{\circ}$ 014-2011-TR, esta se declararía con efecto retroactivo, lo que implicaría que las empresas que hubiesen resultado "perjudicadas" por laudos condenatorios tendrían el camino expedito para solicitar en vía judicial su nulidad en tanto el arbitraje potestativo que regulo sus actuales relaciones laborales habría desaparecido.

Esta situación probable, inclinaría la balanza a favor de las empresas e indefectiblemente perjudicaría a los trabajadores hasta entonces beneficiados, lo cual materializado a través de una simple medida cautelar podría conllevar en el mejor de los supuestos a suspender los beneficios conseguidos; y en el peor de sus extremos, a devolver los incrementos generados.

Conforme a lo señalado, consideramos que en tanto la declaratoria de nulidad no haya sido consentida a la fecha, resulta preponderante corregir los errores detectados en la técnica normativa propuesta y viabilizar a través un mecanismo técnico normativo la vigencia de los laudos que hasta la fecha hubiese sido consentido. 


\subsection{PROBLEMAS EN LA APLICACIÓN DEL ARBITRAJE POTESTATIVO}

\subsubsection{El arbitraje potestativo incausado.}

A efectos de establecer la problemática del arbitraje incausado, resulta necesario, en primer lugar, definir nuevamente y de manera muy genérica la definición de arbitraje potestativo causado (o únicamente arbitraje potestativo), en los parámetros señalados en el Decreto Supremo $N^{\circ}$ 014-2011-TR, para luego resaltar sus diferencias en contra posición del arbitraje potestativo incausado.

Conforme se ha señalado precedentemente, el arbitraje potestativo se configura cuando una de las partes tiene la capacidad de exigir a la otra heterocomponer un desacuerdo a través de la intervención de un árbitro. La materialización de este mecanismo se sujetará exclusivamente a la existencia de dos supuestos:

a) Cuando las partes no se pongan de acuerdo en la primera negociación, en su nivel o contenido y, el segundo lugar,

b) Cuando se advierten actos de mala fe que tengan por efecto dilatar, entorpecer o evitar el acuerdo.

Queda claro entonces, que cuando la motivación del inicio de un arbitraje radique en estas dos causales, indefectiblemente nos encontraremos ante un arbitraje potestativo causado.

Ahora bien, si el arbitraje potestativo causado se fundamenta en causales determinadas por la norma, naturalmente, el arbitraje incausado se establecerá cuando una de las partes obligue a la otra, "bajo el amparo de la ley", y sin que medie causal alguna. 
En la actualidad, es habitual que los sindicatos invoquen la aplicación del arbitraje potestativo amparando su petición en lo estipulado en el artículo $61^{\circ}$ de la Ley de Relaciones Colectivas de Trabajo, y contrario a lo que se podría esperar, diversos tribunales, tanto arbitrales como constitucionales ${ }^{19}$ ampararán dicho pedido.

Frente a esto, nosotros consideramos que esta posición debe ser rechazada en tanto el arbitraje potestativo incausado contraviene mandatos constitucionales ${ }^{20}$, pues no promueve la negociación colectiva y ni la promoción de las formas de solución pacífica de los conflictos laborales.

La promoción de la negociación colectiva, conforme a los parámetros establecidos por la Constitución, debe fomentar condiciones viables que permitan a las partes establecer de manera directa la regulación de su relación laboral. Es decir, el fomento planteado debe evitar principalmente que la solución de una controversia laboral sea objeto de determinación por parte de un tribunal arbitral, en tanto no necesariamente estos se encuentran capacitados para entender la vivencia diaria de la dirección de la empresa ni el esfuerzo o desgaste de los trabajadores. En este caso, no necesariamente sus decisiones sean la mejor opción para establecer una solución reguladora óptima inter partes.

Conforme a lo señalado, consideramos que lo primero que debería promover la norma es el acuerdo en trato directo para lo cual el Estado debe estimular escenarios para que las

\footnotetext{
${ }^{19}$ Sentencia del 21 de mayo de 2014, recaída en el Expediente No. 03243-2012-PA/TC.

${ }^{20}$ Artículo $28^{\circ}$.- El Estado reconoce los derechos de sindicación, negociación colectiva y huelga. Cautela su ejercicio democrático: 1. Garantiza la libertad sindical. 2. Fomenta la negociación colectiva y promueve formas de solución pacífica de los conflictos laborales. La convención colectiva tiene fuerza vinculante en el ámbito de lo concertado. 3. Regula el derecho de huelga para que se ejerza en armonía con el interés social. Señala sus excepciones y limitaciones.
} 
partes negocien en trato directo y no opten "tan fácilmente" por una posición que traslade sus responsabilidades a terceros.

Sobre el particular, queda claro entonces que el arbitraje, a través de cualquiera de sus formas, no puede ni debe comprometer el fomento de la negociación directa, siendo el caso que debe constituirse (el arbitraje) en una herramienta complementaria de última instancia y no una alternativa de esta.

\subsubsection{La desnaturalización del arbitraje de opción.}

En la actualidad, conforme a lo señalado en el artículo $65^{\circ 21}$ del Texto Único Ordenado (TUO) de la Ley de Relaciones Colectivas de Trabajo (LRCT), el laudo que resuelve un arbitraje, sea este obligatorio, voluntario o potestativo, no puede "establecer una solución distinta a las propuestas finales de las partes ni combinar planteamientos de una y otra". Sin embargo, señala en un segundo párrafo que por la naturaleza de su fallo podrá atenuar posiciones extremas".

Del artículo antes mencionado, se desprende que nuestro marco regulatorio prevé un mecanismo similar al arbitraje denominado de oferta final ${ }^{22}$, según el cual el tribunal arbitral debe optar por las propuestas de las partes en su integridad, no teniendo la facultad de combinarlas o modificarlas, salvo cuando tenga que atenuar posiciones extremas. Este

\footnotetext{
${ }^{21}$ Artículo 65.- El laudo no podrá establecer una solución distinta a las propuestas finales de las partes ni combinar planteamientos de una y otra.

El laudo recogerá en su integridad la propuesta final de una de las partes. Sin embargo, por su naturaleza de fallo de equidad, podrá atenuar posiciones extremas.

${ }^{22}$ SINGH, Ramsumair. "Final Offer Arbitration in theory and practice". En: Industrial Relations Journal, vol. $\mathrm{N}^{\circ} 17,1986$, pp. 329-338.
} 
análisis ha sido recogido por la Corte Suprema ${ }^{23}$, donde señala de manera concluyente que el sistema escogido por la LRCT es el del arbitraje de oferta final.

Conforme ha sido señalado en el acápite referido a la oferta final, reiteramos que el objetivo que subyace a este tipo de arbitraje radica en incentivar negociaciones de buena fe que promuevan que las partes del litigio formulen ofertas razonables y, de este modo evitar la generación de una dependencia de las partes de recurrir al arbitraje como medio para solucionar sus conflictos.

En tal sentido, consideramos también que el arbitraje de oferta final, conforme a lo señalado en el artículo $65^{\circ}$ del TUO de la LRCT, al optar íntegramente por alguna de las propuestas señaladas por las partes, generará indefectiblemente duda respecto del resultado que tendrá el laudo arbitral, pues el Tribunal Arbitral al no poder modificar las propuestas presentadas por puntos intermedios, promoverá indirectamente que las partes opten por soluciones consensuadas a través de las cuales el convenio colectivo arribado será producto de su voluntad y no de la decisión de un tercero.

El arbitraje de oferta final, en tanto persigue evitar la necesidad de recurrir al arbitraje, se alinea con los preceptos señalados en el artículo $28^{\circ}$ de la Constitución, en tanto promueve incentivos para que las partes formulen propuestas más adecuadas en trato directo y mejoren sus estrategias de negociación.

En el Perú, conforme a las estadísticas brindadas por el Ministerio de Trabajo y Promoción del Empleo, del análisis de laudos registrados ante la Dirección General de Trabajo (DGT) durante los años 2012, 2013, 2014, 2015 y 2016 se procesaron 122 laudos arbitrales, de los cuales 50 de ellos fueron voluntarios y 72 potestativos, siendo el caso que

\footnotetext{
${ }^{23}$ Véase por todas la sentencia de la Corte Suprema recaída en el Expediente $N^{\circ}$ 14428-2016-AREQUIPA.
} 
de los de los 72 laudos arbitrales potestativos analizados solamente 4 de ellos no fueron modificados.
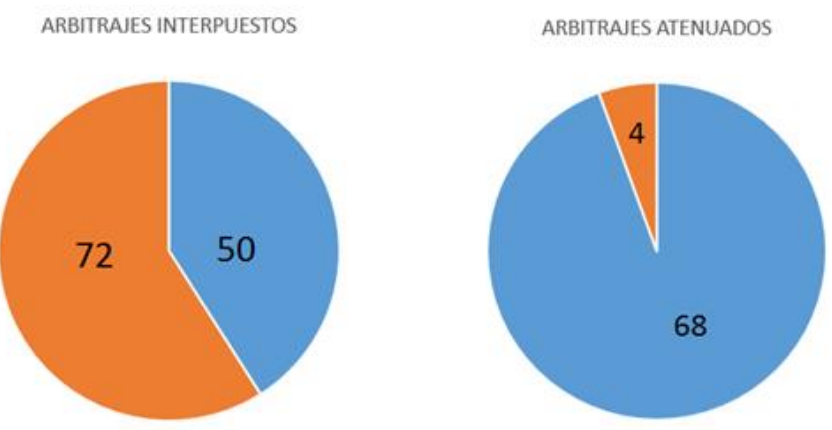

Estando a que del $100 \%$ de los laudos potestativos registrados durante los últimos 5 años únicamente el $5.5 \%$ de ellos no fueron modificados por tribunales arbitrales, consideramos conveniente que la facultad de atenuación, señalada en el segundo párrafo del artículo $65^{\circ}$ de TUO de la LRCT, sea eliminada de la misma, a fin de evitar las distorsiones presentadas a pesar de que la regulación actual establece que la atenuación es meramente excepcional.

\section{CAPÍTULO III}

SOLUCIONES PLANTEADAS A LOS PROBLEMAS DE APLICACIÓN

DEL ARBITRAJE POTESTATIVO 
En capítulos anteriores hemos desarrollado la parte general y la problemática que tiene la aplicación del arbitraje potestativo en la negociación colectiva y la promulgación de varias normas que en el tiempo han modificado su sentido y objetivo.

Nuestra posición se centra en que el arbitraje potestativo no debe ser aplicado conforme la regulación actual, sino por lo contrario, debería regularse conforme a los parámetros constitucionales vigentes. En tal sentido, procederemos a detallar la solución a los problemas que hemos identificado en el capítulo anterior.

\subsection{SOLUCIONES A LOS PROBLEMAS DETECTADOS}

\subsubsection{En relación a la vulneración del principio de prelación normativa}

En base a lo señalado en el numeral 2.2.1, 2.2.3 y 2.2.4 del Capítulo II sobre las modificaciones que realizan dos Decretos Supremos al Reglamento de la Ley de Relaciones Colectivas de Trabajo (Decretos Supremos $N^{\circ}$ 014-2011-TR y N ${ }^{\circ}$ 009-2017-TR) y la incorporación de los supuestos de mala fe en que pueda incurrir una de las partes y la incorrecta valoración de los supuestos de procedencia del arbitraje potestativo a través de una Resolución Ministerial N ${ }^{\circ}$ 284-2011-TR, corresponde señalar que dichas normas vulneran el principio de prelación normativa consagrado en el artículo $51^{\circ}$ de la Constitución Política del Perú que menciona: "La Constitución prevalece sobre toda norma legal; la ley, sobre las normas de inferior jerarquía, y así sucesivamente. La publicidad es esencial para la vigencia de toda norma del Estado".

En tanto que el Decreto Supremo N 014-2011-TR y N 009-2017-TR y la Resolución Ministerial $\mathrm{N}^{\circ}$ 284-2011-TR son contrarios a la Ley, puesto que contravienen el actual 
sentido de la norma, proponemos como medida de solución, modificar el artículo $61^{\circ}$ de la Ley de Relaciones Colectivas de Trabajo (LRCT), y clasificar su contenido en dos momentos (párrafos): el primero referido al arbitraje voluntario y el segundo al arbitraje potestativo.

Con esta nueva redacción, el primer párrafo del artículo $61^{\circ}$ de la LRCT, mantendría el mismo sentido del actual artículo $61^{\circ}$, en tanto la modificación propuesta no busque alterar la regulación actual, y esto es que el arbitraje voluntario siempre sea una posibilidad; sin embargo, consideramos necesario añadir en un segundo párrafo al arbitraje potestativo incluyendo dentro de su contenido los requisitos ${ }^{24}$ fijados actualmente en el artículo 61-A del Reglamento de la LRCT.

Con esta modificación, buscamos dotar al arbitraje potestativo, parametrado bajo ciertas circunstancias de procedencia, de fuerza de ley. En tal sentido, al normar el arbitraje potestativo en una ley, proponemos la derogación de los Decretos Supremos N 014-2011TR y Nº09-2017-TR y la Resolución Ministerial N²84-2011-TR.

\subsubsection{En relación a la atenuación por parte de los árbitros}

De lo señalado en el numeral 2.3.2 del Capítulo II, respecto a la potestad que tiene el Tribunal Arbitral y conforme a lo dispuesto en el artículo $65^{\circ}$ del Texto Único Ordenado de la Ley de Relaciones Colectivas, de poder atenuar posiciones extremas, consideramos que dicha posición contraviene la finalidad del arbitraje potestativo en tanto arbitraje de oferta final.

\footnotetext{
${ }^{24}$ dos causales: (i) que no se haya arribado a un acuerdo en la primera negociación sobre el nivel o contenido; $\mathrm{y}$, (ii) que durante la negociación se hayan advertido actos de mala fe tendientes a entorpecer la posibilidad de arribar a un acuerdo.
} 
Conforme a lo precisado 1.4, el arbitraje de oferta final consiste en que las partes del proceso presenten ante el tribunal su propuesta final, a efectos de que este órgano colegiado elija, en base a criterios de equidad y justicia, cuál posición resulta adecuada para resolver la materia controvertida.

De la información recabada por la Dirección General de Trabajo, se tiene que entre el año 2012 y 2016 se emitieron 122 laudos arbitrales, de los cuales 49 correspondían al sector privado y 73 al sector público.

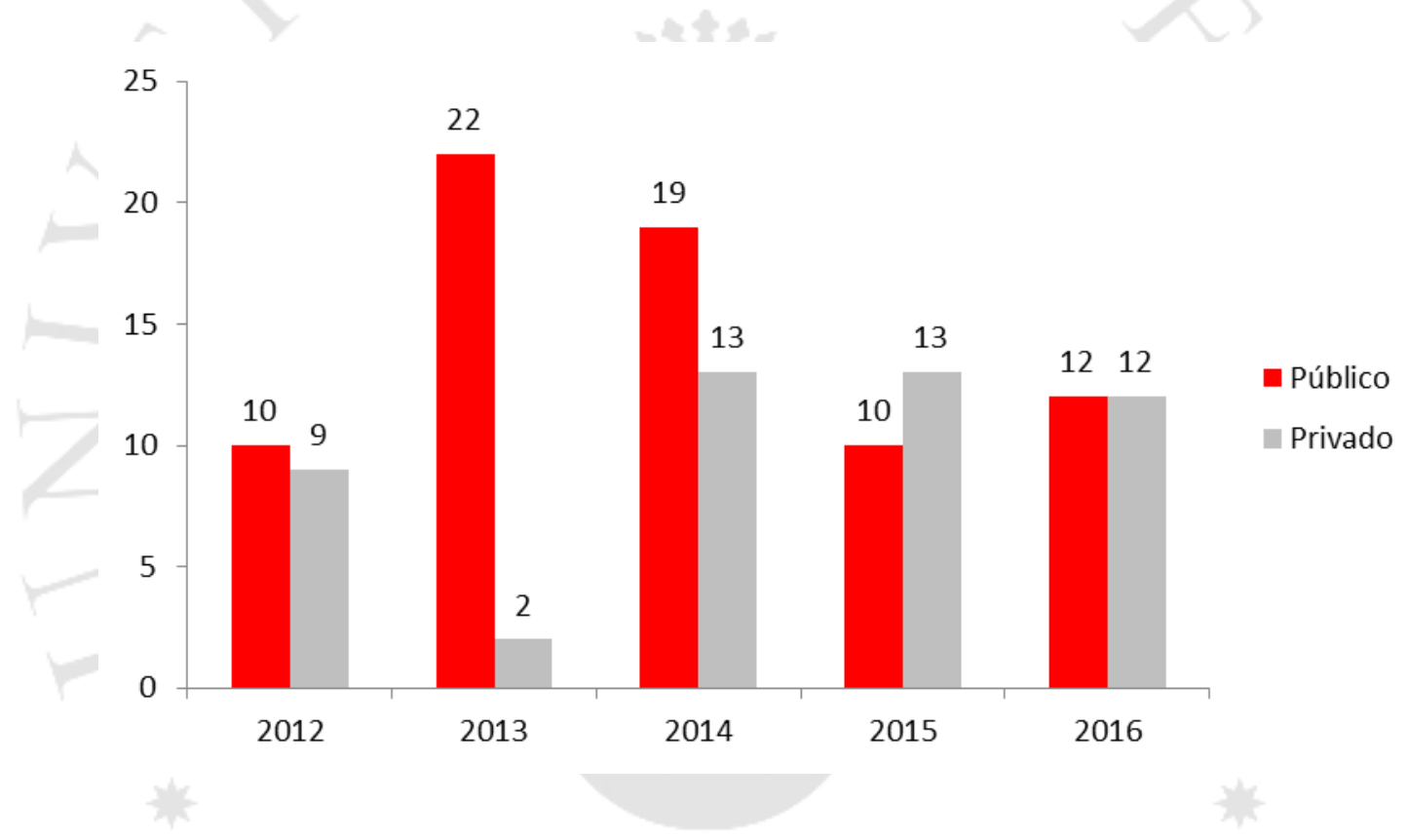

Con respecto a la naturaleza del arbitraje, de los 122 laudos antes mencionados, 72 laudos recayeron sobre arbitrajes potestativos y 50 sobre arbitrajes de naturaleza voluntaria.

Del total de los 122 laudos revisados (que incluye arbitrajes voluntarios y potestativos), el 92\% (112 laudos) correspondían a laudos sujetos a atenuación, siendo únicamente el 8\% restante (10 laudos arbitrales) laudos no sujetos a variación alguna; de estos, 4 de ellos corresponden a arbitrajes potestativos y 6 a voluntarios. 
Recordando que de los 122 laudos analizados, 72 correspondían a arbitrajes potestativos y únicamente en 4 de ellos no se realizó ningún tipo de atenuación, tenemos un total de 68 laudos sobre los cuales se puede analizar dos tipos de atenuación: a) la atenuación parcial, que hace referencia a los laudos en los que no se atenuaron todas las cláusulas de la propuesta adoptada y b) la atenuación integral, refiere a la atenuación de todas las cláusulas.

Del total de arbitrajes sujetos a atenuación (68 laudos), 46 fueron arbitrajes fueron sujetos a atenuación parcial, mientras que los 22 restantes fueron sujetos a atenuación integral.

De lo expuesto, y conforme ya ha sido explicado en el capítulo precedente, el espíritu del artículo $65^{\circ}$ de la LRCT previó un mecanismo similar al denominado arbitraje de péndulo o de oferta final ${ }^{25}$. En tal sentido, estando a que del $100 \%$ de los laudos potestativos registrados durante los últimos 5 años, únicamente el $5.5 \%$ de ellos no fueron modificados por tribunales arbitrales, consideramos conveniente que la facultad de atenuación, señalada en el segundo párrafo del artículo $65^{\circ}$ de TUO de la LRCT, sea eliminada a efectos de: a) incentivar negociaciones de buena fe; b) fomentar que las partes formulen propuestas razonables; c) aumentar la probabilidad de que se arribe a un acuerdo antes de que el Tribunal Arbitral se pronuncie sobre el fondo; d) evitar la generación de una dependencia de las partes de recurrir al arbitraje como medio para solucionar sus conflictos y e) evitar que el arbitraje reproduzca micro-negociaciones, en las cuales los árbitros escogen propuestas mixtas o alteren las propuestas de las partes.

\subsubsection{En relación al arbitraje potestativo incausado}

\footnotetext{
${ }^{25}$ Mecanismo a través del cual los árbitros deben escoger las propuestas de las partes en su integridad, sin poder combinarlas ni modificarlas.
} 
En base a lo señalado en el numeral 2.3.1 del Capítulo II, referido a la problemática de la admisión de los arbitrajes potestativos incausados, corresponde reiterar, en primer término, que el presente trabajo considera fundamental resaltar el hecho que no existe mejor mecanismo de solución de conflictos laborales (entre empresas y sindicatos) que el que se resuelve de manera directa a través de una negación colectiva. Este hecho se fundamenta en que no existe nadie mejor que las partes (empresas y sindicatos), que entienden la realidad de la empresa, para establecer una solución razonable y equitativa a justos reclamos.

En esa misma línea, consideramos que el arbitraje potestativo solo puede justificarse cuando este estimula la negociación directa. En tal sentido, tiene coherencia que este se admita en primera negociación o cuando se compruebe de manera fehaciente la mala fe de una de las partes para, por ejemplo, entorpecer el arribo de un acuerdo.

Remitiéndonos nuevamente al artículo $28^{\circ}$ de la Constitución, podemos colegir válidamente, que el espíritu de la norma no es promover el arbitraje potestativo en desmedro de la negociación colectiva. En tal sentido, al admitirse arbitrajes que no se enmarcan en el estímulo de la negociación colectiva se desaparecen los incentivos para la negociación directa.

En síntesis, el arbitraje incausado desnaturaliza la negociación colectiva y transforma de un diseño normativo de promoción del diálogo a uno que promoción del arbitraje.

Conforme a lo señalado, y en la misma línea del numeral 3.1.1., proponemos como medida de solución modificar el artículo $61^{\circ}$ de la Ley de Relaciones Colectivas de Trabajo 
(LRCT), circunscribiendo la procedencia del potestativo únicamente a las causales expresadas dentro de su contenido.

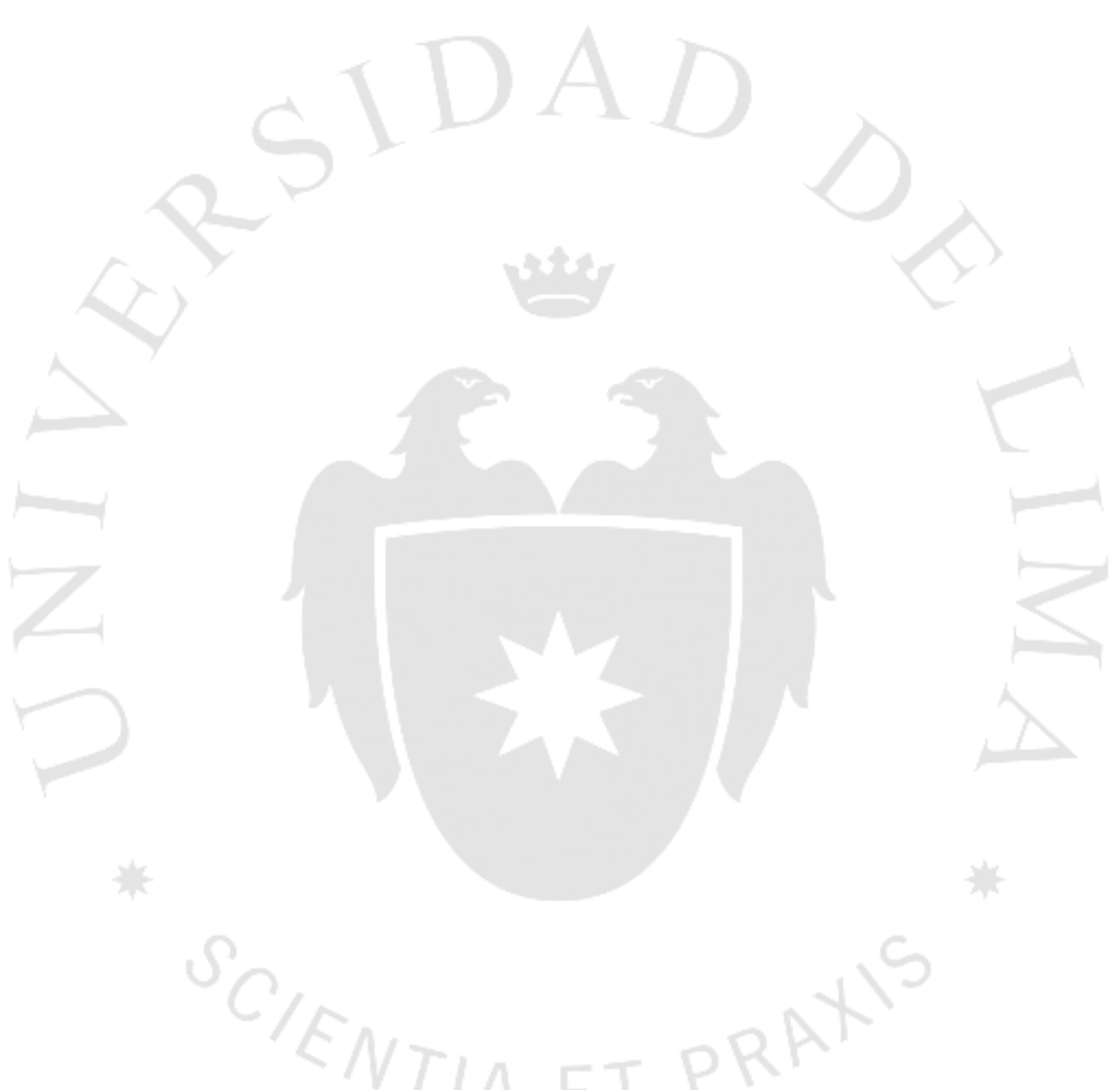

\subsection{PROYECTO DE LEY QUE SUBSANA LOS PROBLEMAS DETECTADOS}

\section{PROYECTO DE LEY}

\section{EL PRESIDENTE DE LA REPÚBLICA}

POR CUANTO: 
El Congreso de la República

ha dado la Ley siguiente:

EL CONGRESO DE LA REPÚBLICA

Ha dado la Ley siguiente:

LEY QUE MODIFICA EL TEXTO ÚNICO ORDENADO DE LA LEY DE

RELACIONES COLECTIVAS DE TRABAJO, APROBADO POR DECRETO

$\underline{\text { SUPREMO } N^{\circ} 010-2003-T R}$

Artículo 1.- Modificación de artículos del Texto Único Ordenado de la Ley de Relaciones Colectivas de Trabajo

Modificase los artículos 61 y 65 del Texto Único Ordenado de la Ley de Relaciones Colectivas de Trabajo, aprobado por Decreto Supremo $N^{o}$ 010-2003-TR, los que quedan redactados de la siguiente manera:

Artículo 61.- Si no se hubiese llegado a un acuerdo en negociación directa o en conciliación, de haberla solicitado los trabajadores, podrán las partes someter el diferendo a arbitraje.

Cualquiera de las partes podrá recurrir al arbitraje potestativo solo en el caso de la primera negociación, cuando no exista acuerdo en su nivel o su contenido; o, cuando durante la negociación se adviertan actos de mala fe que tengan por efecto dilatar, entorpecer o evitar el logro de un acuerdo. El arbitraje potestativo no requiere de la suscripción de un compromiso arbitral. 
En ningún caso, el arbitraje potestativo puede ser utilizado en desmedro del derecho de huelga.

Artículo 65.- El laudo no podrá establecer una solución distinta a las propuestas finales de las partes ni combinar planteamientos de una y otra; debe recoger en su integridad la propuesta final de una de las partes. El Árbitro o Tribunal Arbitral no podrán modificar o atenuar las propuestas finales formuladas por las partes.

Para la decisión deberán tenerse presente las conclusiones del dictamen a que se refiere el artículo 56."

\section{Artículo $2^{\circ}$. - Incorporación de artículos al Texto Único Ordenado de la Ley de Relaciones Colectivas de Trabajo}

Incorpórense los artículos 61-A, 61-B y 61-C del Texto Único Ordenado de la Ley de Relaciones Colectivas de Trabajo, aprobado por Decreto Supremo No 010-2003-TR, los que quedan redactados de la siguiente manera:

\section{Artículo 61-A.- Designación de los árbitros y presidente del Tribunal Arbitral}

Activado el arbitraje, las partes deben elegir a sus árbitros en un plazo no mayor de cinco (5) días hábiles perentorios. De no hacerlo una de ellas, la Autoridad Administrativa de Trabajo elige al árbitro correspondiente, cuyo honorario asume la parte responsable de su elección.

Elegidos los árbitros, ellos acuerdan la elección del Presidente del Tribunal Arbitral en un plazo no mayor de cinco (5) días hábiles perentorios. De no llegar a un acuerdo dentro del plazo anterior, la Autoridad Administrativa de Trabajo 
procede a la elección del Presidente Del Tribunal Arbitral, quien se desempeñará como tal salvo que las partes, de común acuerdo, propongan un nombre distinto dentro del plazo de tres (3) días hábiles de comunicada la elección a ambas partes.

Las designaciones efectuadas por la Autoridad de Administrativa de Trabajo se realizan mediante sorteos públicos y aleatorios, sobre la nómina de árbitros inscritos en el Registro Nacional de Árbitros de Negociaciones Colectivas, en un plazo no mayor de diez (10) días hábiles desde que se toma conocimiento del vencimiento del plazo para designar al árbitro o Presidente del Tribunal Arbitral.

Salvo pacto en contrario, no puede ser designado como árbitro o Presidente del Tribunal Arbitral quien dentro de los dos (2) últimos años se haya desempeñado como parte, árbitro, abogado o asesor en algún arbitraje laboral colectivo, potestativo o voluntario, seguido por alguna de las partes. Los dos (2) años se contabilizan desde la emisión del laudo arbitral. Se exceptúan de esta disposición los árbitros que sean escogidos en arbitrajes unipersonales.

Si por alguna circunstancia alguno de los árbitros dejara de asistir a más de una sesión o renunciara, la parte afectada debe sustituirlo en el término no mayor de tres (3) días hábiles. En caso de no hacerlo, el presidente del Tribunal Arbitral solicita a la Autoridad Administrativa de Trabajo su sustitución.

Constituido el Tribunal Arbitral, dentro de los cinco (5) días hábiles siguientes, las partes entregan al tribunal su propuesta final, de ser el caso, en forma de proyecto de convenio colectivo, con copia para la otra parte, que le será entregado a éste por el presidente del Tribunal Arbitral. Dentro de los cinco (5) días hábiles 
siguientes, las partes podrán formular al tribunal las observaciones debidamente sustentadas, que tuvieran respecto.

\section{Artículo 61-B.- Reglas especiales para el arbitraje potestativo}

Son aplicables al arbitraje potestativo las reglas del procedimiento arbitral establecidas en los artículos 55, 56, 58, 59, 60 y 61 del Reglamento.

En ningún caso, el arbitraje potestativo puede ser utilizado en desmedro del derecho de huelga."

\section{Artículo 61-C.- Actos de mala fe en la negociación}

Las partes están obligadas a negociar de buena fe y a abstenerse de toda acción que pueda resultar lesiva a la parte contraria, sin menoscabo del derecho de huelga legítimamente ejercitado. Constituyen actos de mala fe en la negociación colectiva, los siguientes:

a) Negarse a recibir el pliego que contiene el proyecto de convenio colectivo de la contraparte, salvo causa legal o convencional objetivamente demostrable. Asimismo, la negativa a recibirlo a través de la Autoridad Administrativa de Trabajo;

b) Negarse a proporcionar la información necesaria sobre la situación económica, financiera, social y demás pertinentes de la empresa, en la medida en que la entrega de tal información no sea perjudicial para ésta;

c) Negarse a entregar la información acordada por las partes o precisada por la Autoridad Administrativa de Trabajo; 
d) No guardar reserva absoluta sobre la información recibida siempre que la misma no sea de carácter público;

e) Negarse a recibir a los representantes de los trabajadores o a negociar en los plazos y oportunidades establecidas en la Ley de Relaciones Colectivas de Trabajo y su Reglamento;

f) Ejercer presión para obtener el reemplazo de los integrantes de la representación de los trabajadores o del empleador;

g) Ejercer fuerza física en las cosas, o física o moral en las personas, durante el procedimiento de negociación colectiva;

h) Los actos de hostilidad ejercidos contra los representantes de los trabajadores o los trabajadores afiliados al sindicato;

i) El incumplimiento injustificado de las condiciones acordadas por las partes para facilitar la negociación;

j) Cualquier práctica arbitraria o abusiva con el objeto de dificultar, dilatar, entorpecer o hacer imposible la negociación colectiva;

k) Ejecutar actos de injerencia sindical, tales como, intervenir activamente en la organización de un sindicato; ejercer presiones conducentes a que los trabajadores ingresen a un sindicato determinado; discriminar entre los diversos sindicatos existentes otorgando a unos y no a otros, injusta y arbitrariamente, facilidades o concesiones extracontractuales; o condicionar la contratación de un trabajador a la firma de una solicitud de 
afiliación a un sindicato o de una autorización de descuento de cuotas sindicales por planillas de remuneraciones; $y$,

l) Discriminar entre trabajadores con el fin exclusivo de incentivar o desestimular la afiliación o desafiliación sindical.

Los actos de mala fe enunciados en los literales anteriores no constituyen una lista taxativa.

La valoración de los supuestos de procedencia del arbitraje potestativo establecidos en el artículo $61^{\circ}$-A, será realizado por el Ministerio de Trabajo y Promoción del Empleo o la instancia que haga de sus veces, y está sujeta para su comprobación a criterios de razonabilidad y proporcionalidad considerando el contexto en el que se producen, el marco de la negociación colectiva y los comportamientos precedentes de las partes en anteriores procesos negociales.

\section{Artículo $3^{\circ}$.- Inclusión del artículo $67^{\circ}$ al Texto Único Ordenado de la Ley de Relaciones Colectivas de Trabajo}

Inclúyase el artículo 67 al Texto Único Ordenado de la Ley de Relaciones Colectivas de Trabajo bajo los criterios señalados a continuación:

\section{Artículo 67.- Creación del Registro Nacional de Laudos Arbitrales de Negociaciones Colectivas}

Créase el Registro Nacional de Laudos Arbitrales de Negociaciones Colectivas que estará a cargo de la Dirección General de Trabajo del Ministerio de Trabajo y 
Promoción del Empleo, el que estará integrado por todos los Laudos Arbitrales emitidos por los árbitros que se encuentra inscritos en el Registro Nacional de Árbitros de Negociaciones Colectivas.

\section{DISPOSICIONES COMPLEMENTARIAS FINALES}

\section{PRIMERA. - Normas complementarias}

El Ministerio de Trabajo y Promoción del Empleo, mediante decreto supremo, emite las normas complementarias necesarias para la correcta aplicación de lo establecido en la presente ley.

\section{SEGUNDA. - Procedimientos en trámite}

Los procedimientos que se encuentren en trámite, a la fecha de entrada en vigencia de la presente ley, concluirán bajo las disposiciones con las que fueron iniciados.

\section{DISPOSICIÓN COMPLEMENTARIA DEROGATORIA}

\section{ÚNICA. - Derogación}

Deróguese las normas que se opongan a la presente Ley. 


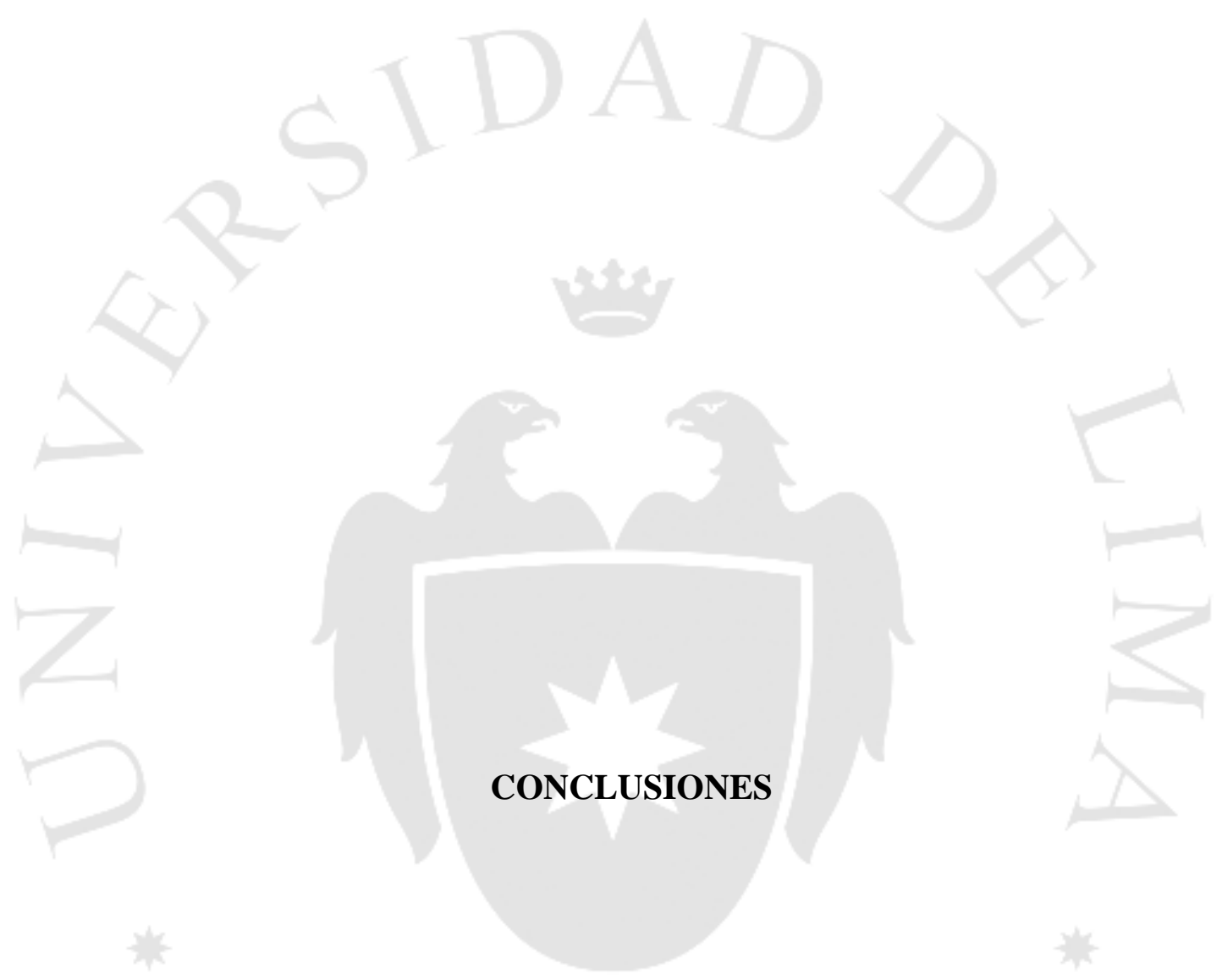

1. La negociación colectiva implica un conjunto de actos previos que buscan a través de concesiones mutuas la celebración de las convenciones colectivas de Trabajo. Este proceso, debidamente fomentado por el Estado, debe permitir a los "contendientes" intercambiar promesas y contraer compromisos formales para la solución de sus diferendos y consecuentemente arribar a un equitativo acuerdo formal de trabajo.

2. Con anterioridad a la dación del Decreto $\mathrm{N}^{\circ}$ 014-2011-TR, la ejecución de una medida de fuerza válida por parte de los trabajadores no generaba en los empleadores suficientes 
incentivos para negociar de manera rápida o cerrar el conflicto a través de un convenio colectivo. En tal sentido, cuando las agrupaciones gremiales no se constituían como una "población relevante" dentro de las compañías, las empresas optaban por negociar "despacio" a fin de desgastar a la contraparte quien a su vez tiene la presión de un resultado inmediato.

3. Frente a la insuficiente generación de incentivos, por parte del Estado para promover negociaciones colectivas que promuevan el trato directo como mecanismo pacifico de solución de controversias laborales, se instauró, como mecanismo regular de resolución de conflictos, el arbitraje potestativo causado e incausado.

4. Que la proliferación de procesos arbitrales potestativos contraviene mandatos constitucionales pues no promueve la negociación colectiva y ni la promoción de las formas de solución pacifica de los conflictos laborales puesto al no ser voluntario, las partes, a efectos de evitar el esfuerzo de una negociación consensuada en trato directo, optan porque un tercero resuelva el conflicto.

5. El arbitraje potestativo al conformarse de la dación de un Decreto Supremo, contraviene el principio constitucional de jerarquía normativa, pues varía a través de una norma reglamentaria, el contenido de una norma de mayor jerarquía (Decreto Ley $\mathrm{N}^{\circ}$ 25593); atenta, de esta manera, contra la seguridad jurídica de las empresas y trabajadores, toda vez que los laudos que se emitan en el marco de esta clase de arbitraje podría ser luego discutidos y dejados sin efecto.

6. Que, sin perjuicio de lo anterior, consideramos que la aplicación del arbitraje potestativo puede en esencia constituirse en una alternativa complementaria (de ultima ratio) para la 
resolución de conflictos laborales siempre y cuando se observe limitaciones a su uso indiscriminado estipulando prohibiciones al arbitraje incausado y a la atenuación de sus laudos.

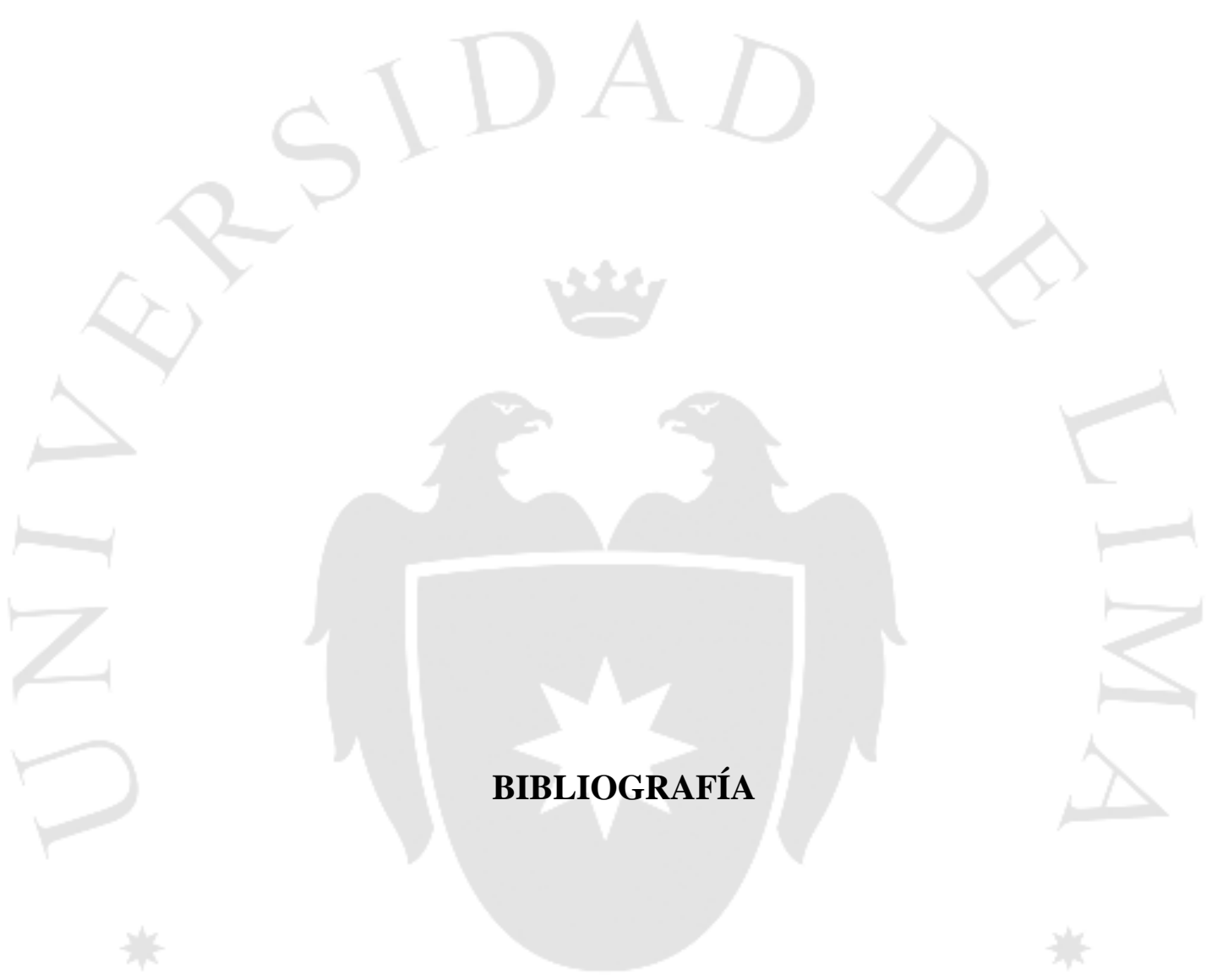

- Texto Único Ordenado de la Ley de Relaciones Colectivas de Trabajo

- Reglamento de la Ley de Relaciones Colectivas de Trabajo

- Decreto Supremo No 014-2011-TR

- $\quad$ Decreto Supremo No 009-2017-TR

- Resolución Ministerial N²84-2011-TR 
- Sentencia del Tribunal Constitucional recaída en el Expediente $\mathrm{N}^{\circ}$ 03561-2009$\mathrm{PA} / \mathrm{TC}$

- Sentencia Aclaratoria del Tribunal Constitucional recaída en el Expediente $\mathrm{N}^{\circ}$ 03561-2009-PA/TC

- Sentencia del 21 de mayo de 2014, recaída en el Expediente No. 03243-2012PA/TC.

- Sentencia de la Corte Suprema recaída en el Expediente $N^{\circ}$ 14428-2016AREQUIPA

- CAIVANO, Roque. Arbitraje. 2da. Ed. AdHoc, Buenos Aires, 2008, P. 50

- ELIAS MANTERO, Fernando, Acerca de la implementación del arbitraje potestativo y la creación del registro nacional de árbitros en materia de negociación colectiva. En Actualidad Laboral. Noviembre 2012

- SINGH, Ramsumair. "Final Offer Arbitration in theory and practice". En: Industrial Relations Journal, vol. ํ17, 1986, P. 329-338.

- KROTOSCHIN Ernesto. Instituciones del derecho del trabajo, $2^{\circ}$ ed. Buenos Aires, 1968. P. 602

- RENDÓN VÁSQUEZ, Jorge. Derecho del Trabajo Colectivo. Quinta Ed. Edit. Edial. Octubre 1998, P. 218

- DIAZ AROCO Teófila T. Derecho Colectivo del Trabajo. Lima, Agosto del 2011, P. 409 
- ROJAS LUGO, Osvaldino. El Desarrollo del Derecho Laboral en Puerto Rico e Iberoamérica y su Interrelación con el Desarrollo Político. Impreso en Puerto Rico por RAMALLO Bros. Printing, INC. 1997, P. 57

- BERMUDEZ TAPIA Manuel. Manual de Arbitraje. Lima. ECB Ediciones S.A.C. Marzo del 2016, P. 200

- ALONSO Olea, Manuel y Casas Baamonde, María Emilia, Derecho del Trabajo, Décima Novena Edición, Civitas Ediciones SL. Madrid 2001, P. 1000

- RODRIGUEZ ROBLERO María Inmaculada. Impugnación de acuerdos sociales y arbitrajes. Tesis Doctoral. Universidad Complutense de Madrid. Madrid, Noviembre de 2009. P. 26

- REQUENA LÓPEZ, Tomás. El principio de jerarquía normativa, Ob. Cit., p. 339. 